\title{
Expression of a human cDNA in moss results in spliced mRNAs and fragmentary protein isoforms
}

\section{Authors:}

Oguz Top ${ }^{1,2, \#, ~ S t e l l a ~ W . ~ L . ~ M i l f e r s t a e d t ~}{ }^{1}$, Nico van Gessel $^{1}$, Sebastian N. W. Hoernstein ${ }^{1}$, Bugra Özdemir ${ }^{1}$, Eva L. Decker ${ }^{1}$, Ralf Reski ${ }^{1,2,3,4^{*}}$

${ }^{1}$ Plant Biotechnology, Faculty of Biology, University of Freiburg, Schänzlestr. 1, 79104 Freiburg, Germany

${ }^{2}$ Spemann Graduate School of Biology and Medicine (SGBM), University of Freiburg, 79104 Freiburg, Germany

${ }^{3}$ CIBSS - Centre for Integrative Biological Signalling Studies, Schänzlestr. 18, 79104 Freiburg, Germany

${ }^{4}$ Cluster of Excellence livMatS @ FIT - Freiburg Center for Interactive Materials and Bioinspired Technologies, University of Freiburg, Georges-Köhler Allee 105, 79110 Freiburg, Germany

ORCID IDs: 0000-0003-2820-6505 (O.T.), 0000-0003-3357-4177 (S.W.L.M.), 0000-0002-0606-246X (N.v.G.), 0000-0002-2095-689X (S.N.W.H.), 0000-0001-9823-0581 (B.Ö.), 0000-0002-9151-1361 (E.L.D.), 0000-0002-5496-6711 (R.R.)

\#Current address: Plant Molecular Cell Biology, Department Biology I, LMU Biocenter, LudwigMaximilians-University Munich, Großhaderner Str. 2-4, 82152, Planegg-Martinsried, Germany

*To whom correspondence should be addressed: Tel: +49 761203 6969; Fax: +49 761203 6967; Email: ralf.reski@biologie.uni-freiburg.de

\section{ABSTRACT}

Production of biopharmaceuticals relies on the expression of mammalian cDNAs in host organisms. Here we show that the expression of a human cDNA in the moss Physcomitrella patens generates the expected full-length and four additional transcripts due to unexpected splicing. This mRNA splicing results in non-functional protein isoforms, cellular misallocation of the proteins and low product yields. We integrated these results together with the results of our analysis of all 32,926 protein-encoding $P$. patens genes and their 87,533 annotated transcripts in a web application, phys $\mathrm{CO}$, for automatized codon-optimization. A thus optimized cDNA results in about eleven times more protein, which correctly localizes to the ER. An analysis of codon preferences of different production hosts suggests that similar effects also occur in non-plant hosts. We anticipate that the use of our methodology will prevent so far undetected mRNA heterosplicing resulting in maximized functional protein amounts for basic biology and biotechnology.

\section{KEYWORDS}

alternative splicing / cryptic introns / intron engineering / biopharmaceutical production / blood coagulation factor IX / complement regulator / factor $\mathrm{H}$ / heterologous expression systems / aberrant mRNA-splicing / Physcomitrella patens / heterosplicing 
bioRxiv preprint doi: https://doi.org/10.1101/2020.09.30.320721; this version posted October 1, 2020. The copyright holder for this preprint

\section{INTRODUCTION}

The majority of eukaryotic genes comprise multiple exons interspersed by noncoding introns, the number and length of which vary between species. The human genome size (GRCh38.p13, Genome Reference Consortium Human Build 38 patch release 13) is 3,099,706,400 bp compromising 20,444 protein-encoding genes, with 8.8 exons and 7.8 introns per gene on average ${ }^{1}$. Generally, human genes have many short exons (average 50 codons) separated by long introns (up to $>10 \mathrm{kbp}$ ) ${ }^{2}$. It is widely accepted that such an exon-intron gene structure emerged during evolution and lead to complex gene regulation and diversification of multicellular eukaryotes ${ }^{2,3}$. Introns that may contain regulatory elements affecting gene expression are removed from pre-mRNAs by RNA splicing. Subsequently, exons are ligated together to generate functional mature mRNAs ${ }^{4}$. Over 30 years of research on pre-mRNA splicing elucidated an underlying complex regulation, which includes exon versus intron recognition ${ }^{5}$, co-transcriptional splicing ${ }^{6}$, alternative splicing ${ }^{7}$, exonic and intronic splicing enhancers and repressors ${ }^{8,9}$, and mRNA export from the nucleus ${ }^{10}$.

Alternative splicing (AS) is a fundamental regulatory process that contributes to proteome expansion ${ }^{11}$. AS can produce multiple mRNAs from the same gene through the preference of splice sites during pre-mRNA splicing. It is modulated based on sequence motifs in the pre-mRNA, the interactions between RNA-binding proteins and splice sites, different cell types, and environmental signals ${ }^{12}$. Splicing is carried out by a large ribonucleoprotein (RNP) complex, the spliceosome, which brings selected exons together by two transesterification reactions ${ }^{13}$. During splicing, uridine (U)-rich small nuclear RNPs (snRNPs) together with non-snRNP splicing factors, and serine/arginine-rich (SR) proteins participate in the recognition of $5^{\prime}$ - and $3^{\prime}$-splice sites as well as the branch site ${ }^{14}$. The core of the spliceosome is highly conserved in all well-characterized eukaryotes ${ }^{3,15}$. The key requirement for splicing is the recognition of a donor splice site by the U1 snRNP ${ }^{16}$. On the other hand, the acceptor splice site, downstream of the polypyrimidine tract, is recognized by the U5 snRNP ${ }^{17}$. Another important splicing element containing the reactive adenosine, the branch point signal, is located upstream of the acceptor splice signal and is important for the formation of the lariat-like intermediate structure ${ }^{17}$. While the majority of the introns have "GT" at the donor splice site and "AG" at the acceptor splice site, in rare cases introns can have unusual dinucleotides: for instance "AT" at the donor site and "AC" at the acceptor site ${ }^{18}$. This class of introns is spliced out of the pre-mRNA by the minor spliceosome $\mathrm{U} 12^{19}$.

Besides its role in proteome expansion, AS controls transcript levels by generating unstable mRNA isoforms that may activate nonsense-mediated mRNA decay (NMD) ${ }^{20}$. Generation of alternative functional mRNAs due to the introduction of premature termination codons (PTC), intron retention, and alternative use of the 5 - and 3 -splice sites causes changes in the localization, stability and/or function of a protein. While in humans more than $95 \%$ of genes encode alternatively spliced mRNAs ${ }^{21}$, in an early study 6,556 out of 39,106 predicted genes showed AS in the basic land plant Physcomitrella patens (moss) with a strong bias towards intron retention ${ }^{22}$. Many PTC-containing alternatively spliced transcripts are NMD targets in P. patens ${ }^{23}$. Furthermore, about half of the AS events altered coding sequences and resulted in 2,380 distinct proteins. In these studies, analysis of AS relied on expressed sequence tags (ESTs) and the alignment of ESTs and CDNA sequences to the genome. The percentage of AS events in $P$. patens is estimated as $58 \%$, but large-scale and/or tissue-dependent profiling of $A S$ in moss by the use of improved sequencing methods may result in a higher percentage ${ }^{24}$.

Two models of splice-site recognition exist ${ }^{25}$ : In the intron-definition model, U1 binds to the upstream donor splice site and U2AF/U2 to the downstream acceptor splice site and branch site of the same intron ${ }^{26,27}$. The length of introns, which probably remain short under evolutionary selection ${ }^{3}$, limits the efficiency of splicing. In lower eukaryotes where introns are shorter, this mechanism might be dominant $^{15}$. In the exon-definition model, the splicing machinery recognizes splice sites flanking the 
same exon ${ }^{28,29}$. This is the major mechanism in higher eukaryotes, where introns are generally longer. Due to these differences, the correct splicing of transgene transcripts has to be considered to maximize the production of a functional protein. For instance, it was necessary to remove a cryptic intron in the coding sequence (CDS) of green fluorescent protein (GFP) from the jellyfish Aequorea victoria to function in the flowering plant Arabidopsis thaliana ${ }^{30}$.

The use of plants as alternative pharmaceutical protein production hosts has been on the rise for the past two decades, and some plant-made products have reached the market ${ }^{31}$. However, the percentage of plant-based biopharmaceuticals in the pharmaceutical market is still minute, mainly because of lower yields compared to prokaryotic and mammalian systems ${ }^{32}$. Nevertheless, they offer alternative solutions in niche areas ${ }^{33}$. Production of blood clotting factors could be such a niche ${ }^{31}$. The human blood-clotting factor IX (FIX), a member of the intrinsic pathway of coagulation, is required for normal hemostasis and its absence or abnormal levels causes hemophilia $\mathrm{B}^{34}$. Current treatment is restricted to protein replacement therapy and factor concentrates costs are between $\$ 100,000$ and $\$ 200,000$ per patient and year ${ }^{35}$. Thus, there is a need for an economic production of FIX, which makes us attempting to produce it in the moss system. The moss $P$. patens, a model organism for evolutionary and functional genomics approaches, is an established host for the production of complex recombinant biopharmaceuticals and proven its suitability for large-scale production ${ }^{36,37}$. The first moss-made drug candidate, moss-aGal for enzyme replacement therapy of Fabry disease, has successfully completed phase I clinical trials ${ }^{38}$. Additionally, a variety of other potential biopharmaceuticals is being produced in moss ${ }^{39-41}$.

In the present study, we report the expression of a human blood clotting factor IX-encoding cDNA in $P$. patens. We show that specific sequence motifs in the FIX mRNA were recognized by the splicing machinery as donor and acceptor sites and produced several different transcripts, which resulted in different protein isoforms. We named this new phenomenon heterosplicing, and were able to prevent it by changing the splice sites and optimizing codons without affecting the FIX aa sequence (optiFIX). Expression of optiFIX resulted in full-length transcripts only, and an eleven-fold increase of protein accumulation. In addition, we found heterosplicing also in transgenic moss lines expressing the CDS of human factor $\mathrm{H}(\mathrm{FH}) \mathrm{CDS}$. By optimizing the sequence, we generated optiFH, which showed no heterosplicing and yielded significantly enhanced $\mathrm{FH}$ protein abundances in vivo. We suggest that our methodology of CDS optimization will provide a better quantification of transcript levels, and precise detection, purification, and quantification of functional proteins. It may reduce the bioenergetic costs of heterologous cDNA expression by preventing the formation of non-functional products and maximizing functional recombinant protein production, major bottlenecks in plant-based systems.

\section{RESULTS}

\section{Predicted miRNA activity is inhibited by mutating miRNA binding sites}

MicroRNAs can regulate gene expression at the posttranscriptional level, either via target mRNA degradation or translational inhibition. The possible actions of $P$. patens miRNAs on the RNA sequence for human Factor IX (NCBI reference NM_000133) were investigated using psRNATarget (http://plantgrn.noble.org/v1_psRNATarget/). Thus, two miRNAs were identified (miR1028c-3p and miR1044-3p), that might interfere with FIX expression in this moss. The respective binding sites on the FIX RNA sequences were modified in the DNA construct without a change in the FIX aa sequence. The potential binding site of ppt-miR1028c-3p, which might inhibit translation, was changed into ATCATGTGAGCCAGCTGTACCC between positions 495 and 516 . The binding site of ppt-miR1044-3p, which might lead to cleavage of the FIX RNA, was mutated into 
bioRxiv preprint doi: https://doi.org/10.1101/2020.09.30.320721; this version posted October 1, 2020. The copyright holder for this preprint

AGGGTAAGTACGGCATCTAT between positions 1304 and 1323. The sequence of miRNAs and their binding sites as well as the maximum energy to unpair the target site (UPE) and expectation value are shown in Supplementary Table 1.

\section{Splicing of FIX mRNA occurs in transgenic plants and in transiently transfected cells}

The native FIX signal peptide was replaced by the moss aspartic proteinase signal peptide of PpAP1 to target the protein to the secretory pathway for its proper posttranslational modifications ${ }^{42}$. After transfection of the parental moss line $\Delta x t / f^{41}$ with the human FIX-encoding, cDNA-based expression construct that comprises the complete FIX coding sequence (CDS) of 1401 bp without any introns; 49 transgenic moss lines were regenerated and screened. The presence and integration of the full-length FIX CDS in the moss genome was confirmed via PCR (Supplementary Fig. 1). In order to validate the completeness of the FIX transcripts, RT-PCR was performed with primers spanning the complete CDS. In addition to the full-length transcript, several smaller products occurred (Fig. 1). In cDNA from the juvenile moss protonemal tissue, PCR products of discrete sizes were detected ranging from $~ 700$ to $1370 \mathrm{bp}$ (Fig. 1a). Sequencing of the PCR products revealed that five of the observed bands were FIX-specific products with a length of $1371 \mathrm{bp}, 1240 \mathrm{bp}, 895 \mathrm{bp}, 769 \mathrm{bp}$, and $691 \mathrm{bp}$, respectively. Apparently, unexpected splicing of the FIX mRNA produced the smaller aberrant transcripts. To analyze this phenomenon across different tissues, we repeated the same procedure with RNA isolated from adult plants (gametophores). FIX transcripts detected in gametophores were consistent with those from protonema (Fig. 1b).

The sequencing of different PCR products revealed that specific motifs along the human FIX mRNA were recognized as splice signals in $P$. patens. The spliced transcripts were identical in all 49 transgenic lines and in 2 different moss tissues. Hence, we conclude that different transcripts were exclusively derived from unexpected splicing of the mRNA transcribed from the complete FIX CDS, and not by a partial integration of the FIX expression construct into the $P$. patens genome. PCRs from genomic DNA support this conclusion (Supplementary Fig. 1).

In order to scrutinize the presence of spliced FIX CDS variants in transiently transfected cells (protoplasts), total RNA was extracted from cells 14 days after transfection. After RT-PCR, FIX CDS variants with varying lengths occurred. Like in the RT-PCR from transgenic lines, 5 FIX CDS variants (1 full-length and 4 aberrant spliced FIX transcripts) were confirmed in these protoplasts (Fig. 1c). Thus, we found an unexpected splicing of an mRNA transcribed from a human full-length cDNA in moss, a phenomenon we henceforth name heterosplicing.

\section{Spliced FIX transcripts and splice-site analysis}

Splice junctions within the FIX mRNA were revealed by sequencing. The splicing of the primary transcripts from human FIX cDNA in moss caused the production of four alternative products (Fig. 2a): i. deletion of a 44 aa long domain in the part coding for the heavy chain (Fig. 2a.ii), ii. large deletion in the part coding for the light chain (115 aa) together with the absence observed in the heavy chain (Fig. 2a.iii), iii. nearly complete absence of the sequence coding for the light chain and parts of the activation peptide domain (157 aa) and the heavy chain (Fig. 2a.iv), iv. nearly complete lack of the sequence encoding the light chain, complete absence of the activation peptide domain (186 aa) and the sequence representing 41 aa of the heavy chain (Fig. 2a.v). The heavy chain harbors a serine protease domain, which is responsible for the activation of Factor $\mathrm{X}$ in the presence of Factor VIII, calcium and phospholipid surfaces following removal of the activation peptide. Any deletion in this domain will interfere with the activity of the FIX protein. The light chain consists of the Gla domain 
bioRxiv preprint doi: https://doi.org/10.1101/2020.09.30.320721; this version posted October 1,2020 . The copyright holder for this preprint (which was not certified by peer review) is the author/funder, who has granted bioRxiv a license to display the preprint in perpetuity. It is made available under aCC-BY-NC-ND 4.0 International license.

followed by two EGF domains. Any loss in these domains will adversely affect the properties of FIX. Therefore, any alterations caused by the heterosplicing will result in the loss of FIX function.

The GT-AG splicing rule applies for almost all eukaryotic genes ${ }^{43}$ and especially $P$. patens accepts control elements originally optimized for mammalian expression systems without a need for adapting these elements ${ }^{44}$. Here, we inferred four different motifs for acceptor and donor sites based on sequencing data. All FIX heterosplice sites followed the GT-AG rule. Moreover, the data revealed that a CAGGT motif is present in the exon-intron junction, i.e. the donor site (Fig. 3a). In the intron-exon junction, the acceptor site, the motif CAG is conserved in 3 out of 4 cases, but the adjacent two nucleotides do not follow any trend.

To analyze whether donor and acceptor sites and their neighboring nucleotides are conserved in $P$. patens, the genomic vicinity of all splice sites of all 87,533 annotated transcripts corresponding to the 32,926 protein-encoding genes of the current $P$. patens genome release v3. $3^{45}$ were retrieved (Fig. $3 \mathrm{~b}, \mathrm{c})$. In alignment with our experimental findings, an in silico-analysis of these transcripts showed that the CAG|GT motif is the most abundant one in both donor and acceptor sites with a fraction of $23 \%$ and $18 \%$, respectively. The full list of splice cites is compiled in Supplementary Tables 2 and 3.

Subsequently, we analyzed the FIX CDS with a moss splice-site prediction tool ${ }^{46}$, but it largely failed to predict the experimentally verified splicing motifs. This might be due to the fact that this tool has been developed several years ago using only 368 donor and acceptor sites ${ }^{46}$ and has not been updated since then.

\section{Detection of truncated mossFIX protein variants and validation by mass spectrometry}

The analyses at RNA level suggested that $P$. patens would produce a full-length FIX protein and four aberrant fragmentary FIX isoforms. To validate this inference, the culture supernatants of transiently transfected cells were precipitated and analyzed with a polyclonal anti-FIX antibody via immunoblot after reduction and alkylation (Fig. 4a). Full-length FIX was expected at a molecular mass of around 52 $\mathrm{kDa}$ and spliced FIX variants were calculated based on the heterospliced transcripts with molecular masses of $47,34,29$, and $27 \mathrm{kDa}$, respectively. Observed bands on the immunoblot could be attributed to these isoforms together with a band at around $40 \mathrm{kDa}$ (potentially a degradation product) and a band at around $70 \mathrm{kDa}$ (potentially dimers of fragmentary protein isoforms). Additionally, we used the other half of the supernatants for mass-spectrometric (MS) determination of FIX-variant peptide sequences. For the MS-database search, protein models for FIX variants derived from the sequenced splice variants were employed.

We detected the peptide VVGGEDAKPGEHNIEETEHTEQKR (Supplementary Fig. 2) in MS analysis after trypsin digestion, which resulted from splicing in the CDS for the heavy chain that led to the loss of 44 aa between the peptides VVGGEDAKP and GEHNIEETEHTEQKR (Fig. 4b; variants II, III, and IV in Fig. 2a). This result confirmed the presence of a predicted FIX variant caused by heterosplicing on an additional level.

\section{Prevention of heterosplicing by codon optimization}

To analyze the effectiveness of mutating donor and acceptor sites on heterosplicing of the FIX mRNA, we created two different FIX CDS versions. In the first one, aspFIX, the codons neighboring the detected splice junctions were modified. $P$. patens was transiently transfected with the resulting aspFIX plasmid. On day 14, the cells were collected and RNA was isolated. RT-PCR and sequencing of the PCR products revealed that there were only two bands representing FIX variants: the full-length FIX CDS and a shorter variant ( $700 \mathrm{bp}$ ) (Fig. 5a). The donor and acceptor sites of the shorter variant were identified (Fig. 5b) and this shorter variant was lacking the nucleotides encoding the light chain, 
AP and parts of the heavy chain (Fig. 5c). Moreover, splicing would cause a frameshift mutation resulting in early stop codons. Although such nonsense mRNAs may be degraded via nonsensemediated mRNA decay (NMD), not all nonsense mRNAs undergo NMD, which was reported e.g. for $P$. patens $^{23}$ and $A$. thaliana ${ }^{47,48}$. In the second attempt, we performed a complete codon optimization of the FIX CDS in the aspFIX construct according to previous studies ${ }^{49,50}$ resulting in the optiFIX sequence with an overall increased GC content. This was used to transiently transfect moss cells. Subsequent RT-PCR analysis and sequencing revealed that the full-length CDS of FIX was the only specific band; formation of any heterospliced FIX variant was not detected (Fig. 5d). The presence of exclusively the full-length CDS was confirmed on protein level via immunoblot analysis (Fig. 5e).

Next, we compared the codon usage bias in $P$. patens to biases of other pharmaceutical production platforms. The codon usage frequencies of under- and over-represented codons for Cys, Glu, Phe, His, Lys, Asn, Gln, and Tyr in P. patens were compared with Spodoptera frugiperda (insect cells), Homo sapiens (HEK cells), Cricetulus griseus (CHO cells), Nicotiana tabacum (tobacco) and Oryza sativa (rice). For instance, the over-represented codon for Cys, TGC, in P. patens (9.8 in thousands) is also an over-represented codon in S. frugiperda, $H$. sapiens, $C$. griseus, and $O$. sativa. On the other hand, this codon is under-represented in N. tabacum and TGT is preferred over TGC for Cys. The synonymous codon usage bias in $P$. patens is similar to codon usage biases in $S$. frugiperda, $H$. sapiens, C. griseus ( $\mathrm{CHO}$ cells), and $O$. sativa (rice), but different from $N$. tabacum (tobacco) (Table 1).

\section{Comparison of protein levels of FIX and optiFIX in vivo}

In order to analyze whether the protein amounts of FIX and optiFIX show any difference in live moss cells, we cloned two fusion constructs, FIX-Citrine and optiFIX-Citrine. Subsequently, we transiently transfected moss protoplasts with these constructs, and performed confocal laser scanning microscopy (CLSM) on day 3 after transfection. A visual analysis of the images revealed that the FIXCitrine signal shows a diffuse localization pattern, which might be due to intracellular mislocalization of aberrant protein isoforms (Fig. 6a). In contrast, optiFIX-Citrine exhibited a complex network-like organization, indicating a proper localization of the protein in the ER (Fig. 6b). Furthermore, the optiFIX-Citrine signal intensity was higher than that of FIX-Citrine. Comparison of mean voxel intensities calculated for FIX-Citrine and for optiFIX-Citrine (3.88 and 41.73, respectively) shows a nearly eleven-fold higher fluorescence intensity after the codon optimization, which had prevented undesired heterosplicing (Fig. 6c).

\section{Automatic codon-optimization of transgenic coding sequences}

In order to automatize the process of $P$. patens-specific codon optimization, we compiled our findings into a JavaScript-based web application: physCO, and made it available at www.plant-biotech.unifreiburg.de. physCO takes as input coding sequences in FASTA format, inspects them codon-wise, substitutes codons where possible according to our findings on codon usage (Table 2) and finally outputs them in FASTA format. In addition, physCO checks the input for consistent lengths, valid start and stop codons and internal, premature stop codons and raises warnings in case it detects irregularities.

\section{Splicing of FH mRNA like FIX occurs in transgenic plants}

In order to test whether heterosplicing is a common phenomenon in $P$. patens upon transgene expression, we analyzed already existing recombinant human complement factor $\mathrm{H}(\mathrm{FH})$-producing moss lines ${ }^{40}$. Our RT-PCR analysis revealed that expression of the human FH CDS in moss generated two transcript variants, the full-length $\mathrm{FH}$ transcript of 3,639 bp and a 1,215 bp FH variant, which could lead to a truncated $\mathrm{FH}$ isoform with a molecular mass of $45.6 \mathrm{kDa}$ (Supplementary Fig. 3). Therefore, we generated with the help of physCO an optimized version of $\mathrm{hFH}$, and named it optiFH. 
bioRxiv preprint doi: https://doi.org/10.1101/2020.09.30.320721; this version posted October 1, 2020. The copyright holder for this preprint

These changes affected 386 of 1213 codons, and increased the GC\% content from $33.9 \%$ to $49.8 \%$ (Supplementary Fig. 4).

To investigate the effects of these alterations in live moss cells, we cloned two fusion constructs, $\mathrm{FH}$ Citrine and optiFH-Citrine. Subsequently, we transiently transfected moss protoplasts with these constructs, and performed CLSM on day 3 after transfection. A visual analysis of the images acquired for $\mathrm{FH}$ and optiFH revealed that while an $\mathrm{FH}$-Citrine signal was not detectable, optiFH-Citrine signal intensity was high and filled the secretory pathway (Supplementary Figure 5). Analysis on FH showed that heterosplicing is not an effect specific for FIX, but a general phenomenon in moss. Therefore, transgene sequences have to be modified using phys $\mathrm{CO}$ prior to transfection for proper transcription and translation.

\section{DISCUSSION}

Heterologous gene expression is of fundamental importance for basic biology and for industrial production. In order to optimize transgene transcription and translation as well as transcript stability, many factors have to be taken into account. Engineering of upstream and downstream regulatory sequences, replacing original signal peptides with host-suitable ones, and optimizing codons according to host codon-usage pattern can be used to improve protein production.

Splicing/alternative splicing is another important factor that alters expression rates by the generation of various transcripts, which create different protein isoforms. Generation of these protein isoforms can affect fundamental characteristics of the protein such as function, activity, intracellular localization, interaction with other molecules, and stability. Moreover, splicing can create a transcript with an early stop codon, which may be degraded by NMD. Thus, it can be hypothesized that modulation of splicing, a neglected point in transgene expression, can improve protein production. For instance, the expression of GFP from the jellyfish Aequorea victoria in $A$. thaliana failed due to aberrant mRNA processing ${ }^{30}$. To avoid AS, generally cDNAs derived from already spliced mRNAs are introduced into the genome of the production host.

We introduced the human FIX cDNA under the control of the PpActin5 promoter and CaMV $35 S$ terminator into the $P$. patens genome. RNA was isolated from protonemata of transgenic lines and RTPCR analysis revealed unexpectedly that a fraction of human FIX mRNA was spliced into four variants in addition to the unspliced full-length transcript, resulting in five mRNAs a different lengths derived from one cDNA. According to RT-PCR analyses, this phenomenon occurred not only in juvenile protonema, but also in adult moss plants. We sequenced these mRNAs and surprisingly found that reading frames had not changed in the four smaller variants in comparison to the mature full-length transcript. This may have happened by a pure coincidence. Alternatively, we may not have been able to detect such putative minor transcripts because they were either too low abundant for RT-PCR, or they have been eliminated by NMD.

The outcome of this heterosplicing was detectable on four levels, by RT-PCR from mRNAs, immunoblot, mass spectrometry of the protein isoforms, and in vivo by confocal imaging showing deviant localization of Citrine reporter fusions. These findings were also reflected in RT-PCR analysis from transiently transfected moss cells. Our observations revealed that heterosplicing of the human FIX mRNA in moss is consistent across different tissues and not dependent on developmental stages. Furthermore, the consistency of heterosplicing in episomally (transiently) FIX-expressing cells indicates that heterosplicing of the FIX mRNA in transgenic lines was neither due to illegitimate or partial integration of the construct into the moss genome nor a locus-specific effect. Moreover, results of PCRs from genomic DNA of transgenic lines supported this conclusion. Unlike a previously reported 
bioRxiv preprint doi: https://doi.org/10.1101/2020.09.30.320721; this version posted October 1, 2020. The copyright holder for this preprint

case, in which expression of full-length GFP transcript and fluorescence were not detectable ${ }^{30}$, we report here for the first time heterosplicing of a human cDNA in a plant. It caused the generation of various FIX mRNA variants and protein isoforms in addition to the complete transcript and protein. Therefore, a possible occurrence of heterosplicing should be analyzed on RNA level, even if a fulllength protein can be detected in heterologous cells.

All splice junctions in the FIX CDS were determined by sequencing. In addition, we identified consensus motifs of donor and acceptor splice sites in the latest $P$. patens genome version ${ }^{45}$ using all 87,533 annotated transcripts that originate from all 32,926 protein-coding genes, and compared them with our experimentally verified motifs. This revealed that $P$. patens, like most eukaryotes, follows the GT-AG splicing rule. The same was true for the cryptic additional introns recognized in the FIX mRNA; obviously, the $P$. patens spliceosome interprets parts of the FIX CDS as intronic sequences. Presumably, moss cells recognize motifs in the human FIX CDS as cis exonic and intronic splicing enhancers. Little is known about exonic and intronic regulatory sequences in plants ${ }^{51,52}$. Moreover, plant introns are different from animal introns in terms of UA- or U-richness, which is crucial for splicing efficiency ${ }^{53}$. Due to these characteristic differences, it is likely that the GC content can affect the characteristics of splice site recognition ${ }^{15}$. The GC content is correlated with many features including gene density ${ }^{54}$, intron length ${ }^{55}$, meiotic recombination ${ }^{56}$, and gene expression ${ }^{57}$. It varies among species, and even along chromosomes ${ }^{58}$. It was shown before that the average GC content in $P$. patens coding sequences is $50 \%{ }^{46}$. The GC content of the human FIX CDS recognized as cryptic additional introns ranged from $38 \%$ to $40 \%$. This remained the same after exclusively mutating the splice sites' environment in aspFIX; even though mutations in the splicing motifs decreased the number of transcripts from five to two, the GC content of the cryptic alternative intron was still only $40 \%$. The shorter transcript was not in frame, but still detectable by RT-PCR. Therefore, we created the fully codon-optimized plasmid optiFIX to check the effect of overall codon optimization on premRNA splicing. A closer comparison of the aspFIX and optiFIX constructs revealed that there was no change in the donor and acceptor sites of the newly emerged cryptic intron. There was, however, an increase of the GC content within the cryptic intron sequence. The GC contents of the sequences previously defined as introns in the FIX and aspFIX constructs increased to $46 \%-50 \%$ in optiFIX. Hence, we conclude that the increase of GC content introduced by the overall codon optimization together with mutating splice sites' environment prevented the heterosplicing, the mis-interpretation of any sequence as intron by the moss spliceosome. As a result, a nearly eleven-fold increase in protein amounts was achieved in transiently transfected moss protoplasts in vivo. As heterosplicing did not cause detectable frameshift mutations, fluorescence signals obtained from the FIX-Citrine construct were the sum of all FIX protein isoforms, full-length and fragmentary, fused to Citrine. Based on this inference and proteins, which were harvested from transient transfection with the FIX construct, and detected on the immunoblot (Fig. 4), we conclude that the prevention of heterosplicing from the optiFIX construct has improved full-length protein amounts in vivo even more than eleven-fold.

Two mechanisms, namely boosted translation rates and the prevention of mRNA degradation via $\mathrm{NMD}$, may contribute to this result. In addition, the protein from the optiFIX construct was solely detectable in the ER, the compartment of choice for correct post-translational modifications and subsequent secretion of the protein. A similar phenomenon was observed in the expression of another transgene in $P$. patens. One example of heterosplicing and its prevention by our methodology is the expression of human complement factor $\mathrm{H}(\mathrm{FH})$. $\mathrm{FH}$ is an important regulator of the alternative pathway in the human complement system. Currently, a recombinant $\mathrm{FH}$ is not available on the market, although it has potential as a biopharmaceutical in the treatment of severe human diseases like atypical hemolytic uremic syndrome (aHUS), age-related macular degeneration (AMD) or C3 glomerulopathies (C3G). The recombinant production of $\mathrm{FH}$, devoid of plant-specific $\mathrm{N}$-linked sugar residues, in $P$. patens resulted in a range of promising biological activities ${ }^{40}$. Moreover, moss-derived $\mathrm{FH}$ is currently being examined for use in Covid-19 treatment (www.elevabiologics.com). RT-PCR 
bioRxiv preprint doi: https://doi.org/10.1101/2020.09.30.320721; this version posted October 1, 2020. The copyright holder for this preprint

analysis in $\mathrm{FH}$-producing stable moss lines revealed that the expression of human FH CDS generated 2 transcript variants, the full-length FH transcript of 3,639 bp and a 1,215 bp FH variant that could lead to the production of an $\mathrm{FH}$ isoform with a calculated molecular mass of $45.6 \mathrm{kDa}$ (Supplementary Fig. 3). We optimized the FH CDS using our bioinformatics tool physCO, described here, to analyze whether the protein amounts of $\mathrm{FH}$ and optiFH show any difference in live moss cells. A visual analysis of the images acquired for $\mathrm{FH}$ and optiFH from transiently transfected moss cells revealed that while $\mathrm{FH}$-Citrine signal intensity is not detectable, optiFH-Citrine signal intensity is high (Supplementary Fig. 5). Thus, an optimization of the currently used CDS of human FH in plants is advantageous for plant-based production.

These findings suggest that the splicing of heterologous mRNAs should be taken into account on a routine basis. In addition, our analysis of synonymous codon usage bias suggests that our methodology to prevent heterosplicing can be directly implemented in organisms, which follow similar codon usage patterns as $P$. patens, such as $O$. sativa, insect or mammalian cells. Our methodology might still be vital in organisms that have different codon usage patterns, such as the species of the genus Nicotiana, e.g. N. tabacum and N. benthamiana. Mutating donor and acceptor sites and their neighboring nucleotides together with replacing codons ending with $A$ or $T$ to $G$ or $C$ may prevent the generation of heterosplice variants.

Why should splice site mutation and codon optimization be employed at the same time rather than codon optimization alone? Although differences between GC-rich and GC-poor genes were not reported in moss, analyses of various plant species can explain why codon optimization might not be sufficient. The GC content of GC-poor CDS in A. thaliana, soybean, pea, tobacco, tomato, and potato ranges from $40-46 \%$ while GC content of introns is $26-31 \% 59$. A similar trend is visible in GC-rich genes: $46-49 \%$ in CDS and $29-31 \%$ in introns. On the other hand, in maize, the GC content is higher: $56 \%$ in GC-poor CDS and $67 \%$ in GC-rich CDS. The GC content of introns in maize is also elevated: $40 \%$ in GC-poor genes and 48\% in GC-rich genes ${ }^{59}$. This shows that the intron/exon definition is not solely dependent on the GC content. Hence, increasing the GC content of cryptic introns to a certain level without mutating splice site motifs might not be sufficient to prevent aberrant mRNA processing.

In general, the analysis of spliced transcripts is beneficial for at least five reasons. (i) It facilitates the reliable quantification of gene expression by designing primers that differentiate between full-length transcripts and shorter variants. (ii) It enables the precise detection and quantification of heterologous proteins by antibodies that differentiate functional isoforms from non-functional ones. (iii) It helps to better purify proteins either by specific antibodies or by size exclusion chromatography. (iv) Optimized cDNAs may result in better detectable reporter proteins in vivo. (vi) Aberrant protein isoforms due to heterosplicing may show mislocalization in cells of the production host and thus may contribute to poorly modified glycoproteins. Prevention of heterosplice variants eventually will improve recombinant protein production and decrease downstream processing costs significantly. Hence, plant-based systems can become an alternative to traditional production platforms. Moreover, it may have implications for basic biology as well, because here the use of heterologous reporter constructs is of vital importance. For these purposes, we developed phys $\mathrm{CO}$, an automated $P$. patens-specific codonoptimization tool, which allows the optimization of transgene expression by the prevention of undesired mRNA splicing. Moreover, our analysis of codon usage patterns indicates that this tool can also be used for insect ( $S$. frugiperda), HEK ( $H$. sapiens), and $\mathrm{CHO}(C$. griseus) cells as well as rice $(O$. sativa). Besides that, we cannot exclude the possibility, that the phenomenon of mRNA splicing here described as heterosplicing is a novel gene regulatory mechanism occurring in eukaryotes in general. 
bioRxiv preprint doi: https://doi.org/10.1101/2020.09.30.320721; this version posted October 1, 2020. The copyright holder for this preprint

\section{MATERIALS AND METHODS}

\section{Design of the expression vectors pFIX, aspFIX, and optiFIX}

The coding DNA sequence for human Factor IX without the native signal peptide was synthesized as $\mathrm{N}$-terminal translational fusion to the signal-peptide coding sequence of PpAP1 (Pp3c5_19520V3.1) ${ }^{42}$ by GeneArt (Thermo Fisher Scientific, Waltham, MA, USA). It was cloned into the pAct5-MFHR1 plasmid ${ }^{41}$ to generate the final FIX expression vector, pFIX. Its expression is driven by the promoter of the PpActin5 gene ${ }^{60}$ and the CaMV 35 S terminator.

Nucleotides involved in splicing were replaced without a change of the FIX aa sequence in the aspFIX plasmid which was synthesized by GeneArt. For codon optimization, two sources, codon usage bias calculated by Hiss et al. ${ }^{49}$ and Kazusa codon usage database ${ }^{50}$ (http://www.kazusa.or.jp/codon/cgibin/showcodon.cgi?species=145481), were used. Unlike a recent report ${ }^{49}$, we decided to exchange the eight under-represented codons for Cys, Glu, Phe, His, Lys, Asn, Gln and Tyr. Under-represented codons were replaced with the over-represented alternative codons (Table 2) via physCO. The optiFIX CDS was synthesized by GeneArt. See Fig. 7 for a multiple sequence alignment of FIX, aspFIX, and optiFIX.

\section{Design of the expression vectors pFH and optiFH}

The previously generated Factor $\mathrm{H}$ expression plasmid $\mathrm{pFH}^{40}$ contains the same promoter and terminator as pFIX. It was used in transient expression assays. The optiFH CDS was deduced via phys $\mathrm{CO}$ and synthesized by GeneArt. It was cloned into the same vector as FH. See Supplementary Fig. 4 for a sequence alignment of $\mathrm{FH}$ and optiFFH.

\section{Transfection and screening of transgenic plants}

The Physcomitrella patens (Hedw.) B.S. $\Delta x t / f t$ moss line, a double knockout line in which the $\alpha 1,3$ fucosyltransferase and the $\beta 1,2$ xylosyltransferase genes had been abolished ${ }^{61}$ (IMSC accession number 40828), was cultured in liquid Knop medium ( $\mathrm{pH} \mathrm{4.5)} \mathrm{one} \mathrm{week} \mathrm{prior} \mathrm{to} \mathrm{transfection} \mathrm{as}$ described previously62 to obtain cells (protoplasts). Protoplast transfection was performed as described ${ }^{63}$ using $50 \mu \mathrm{g}$ of linearized pFIX DNA per transfection. In addition to the generation of transgenic lines, mossFIX was produced transiently by an upscaled transfection protocol based on the proportion of $0.7-1 \mu \mathrm{g}$ DNA of pFIX for $1 \times 10^{5}$ cells. Stable transfectants were selected on solidified Knop medium containing $25 \mu \mathrm{g} / \mathrm{mL}$ hygromycin as described ${ }^{62}$. Cells transiently expressing mossFIX were grown in special regeneration medium $\left(7.5 \mathrm{mM} \mathrm{MgCl} 2 \times 6 \mathrm{H}_{2} \mathrm{O}, 2.6 \mathrm{mM}\right.$ MES, $200 \mathrm{mM} \mathrm{D(-)-}$ Mannitol, $62.6 \mathrm{mM} \mathrm{CaCl} 2 \times 2 \mathrm{H}_{2} \mathrm{O}, 68.4 \mathrm{mM} \mathrm{NaCl}, 2.8 \mathrm{mM} \mathrm{D}(+)$-Glucose monohydrate, $5 \mathrm{mM} \mathrm{KCl}$; pH: 5.6; osmolarity: 550-570 mOsm) and harvested for RNA and protein analyses two weeks after transfection. To analyze whether splicing of FIX was prevented on RNA level, WT cells were also transfected with the aspFIX and optiFIX constructs, respectively, and harvested for RNA isolation two weeks after transfection.

\section{Plant cell culture}

After selection on solidified Knop medium, transgenic lines were cultured under standard conditions in liquid Knop medium ${ }^{64}$. They were subcultured periodically by disrupting the tissue with the use of an Ultra-Turrax (IKA, Staufen, Germany) at a rotational speed of $16,000-18,000 / \mathrm{min}$ for $1 \mathrm{~min}$. Subsequently, they were transferred to fresh medium. 
bioRxiv preprint doi: https://doi.org/10.1101/2020.09.30.320721; this version posted October 1, 2020. The copyright holder for this preprint

\section{Molecular characterization of transgenic lines}

Following the hygromycin selection process, stable lines were characterized by the presence of the FIX transcript. To validate the presence of the transgene in the moss genome, 80-100 $\mathrm{mg}$ (fresh weight) moss material from protonema cultures were disrupted with the use of a stainless steel ball in TissueLyser II (Qiagen, Hilden, Germany) for 1 min with an impulse frequency set to 30. Genomic DNA was extracted using GeneJET Genomic DNA Purification Kit (Thermo Fisher Scientific, Waltham, MA, USA) according to the manufacturer's instructions. Transgene presence and completeness were verified with a standard PCR with the primers FIXfwdB (5'-GGAGTGTTCGATTGGCTTTCT-3') and FIXrevB (5'-TGGTGGTGGTGGGTTAGTTT-3') that amplifies almost the full-length FIX CDS. For transgene expression analysis via reverse transcription (RT)-PCR, 50-100 mg (fresh weight) moss material from protonema cultures were disrupted with the use of a stainless steel ball in TissueLyser II for 2 min with an impulse frequency set to 30 . The material was resuspended in $1 \mathrm{~mL}$ TRIzol ${ }^{\circledR}$ Reagent (Thermo Fisher Scientific), and RNA was isolated according to the manufacturer's instructions. For analysis of gametophores, 5-6 gametophores were collected and RNA isolation was performed as described above. Six micrograms of DNase-treated RNA were used for first strand synthesis with Superscript Reverse Transcriptase III (Thermo Fisher Scientific). The quality of cDNA was controlled with a standard PCR with the primers c45for (5'-GGTTGGTCATGGGTTGCG-3') and c45rev (5'GAGGTCAACTGTCTCGCC-3') corresponding to the gene coding for the ribosomal protein L21. Transgene expression was verified with the primers FIXfwdB and FIXrevB that amplifies almost the full-length FIX CDS. PCR reactions were performed with Phusion high-fidelity DNA polymerase (Thermo Fisher Scientific). The PCR products were examined by standard agarose gel electrophoresis with visualization of DNA by ethidium bromide fluorescence.

\section{Molecular characterization of transiently transfected cells}

Following the transfection, cells were grown in regeneration medium for two weeks ${ }^{65}$. Transiently transfected cells (nearly 3.6 million cells for FIX and aspFIX; 7.2 million cells for optiFIX) were used for transgene expression analysis via RT-PCR. RNA was isolated using the TRIzol ${ }^{\circledR}$ Reagent and RNA was purified through spin columns of Direct-zol TM RNA MicroPrep kit (Zymo Research, Irvine, California, USA) according to the manufacturer's instructions. After DNase-treatment and first-strand synthesis (for the cDNA synthesis: $0.4 \mu \mathrm{g}$ RNA were used for FIX and aspFIX; $2 \mu \mathrm{g}$ RNA were used for optiFIX), the quality of cDNA was controlled with primers c45for and c45rev. Transgene expression was verified again with primers FIXfwdB and FIXrevB.

\section{Analysis of FIX cDNA products}

Amplified products were excised from the gel and purified using QIAEX II Gel Extraction Kit (Qiagen). Sequencing was done by Eurofins Genomics (GATC Sanger sequencing service). In the sequencing reactions, in addition to FIXfwdB and FIXrevB, FIX6deepseq1F (ATGGGGGCATCGAGGAGTGTTCGAT), FIX6deepseq1R (TTCCCCAGCCACTTACATAGCCAGA), and FIXseq6 (CACCAACAACCCGAGTGAAG) were used. The remaining purified products were separately cloned into the pJET vector using the CloneJET PCR Cloning Kit (Thermo Fisher Scientific) according to the manufacturer's instructions. Clones with aberrant insert sizes were selected for plasmid isolation with the GeneJet Plasmid Miniprep kit (Thermo Fisher Scientific). Sequencing was done as described above.

\section{Splicing motif search}

The most recent release of the Physcomitrella patens v3.3 genome annotation ${ }^{45}$, which is available from https://phytozome.jgi.doe.gov/, was used. The splice sites of all 87,533 annotated transcripts 
bioRxiv preprint doi: https://doi.org/10.1101/2020.09.30.320721; this version posted October 1, 2020. The copyright holder for this preprint

from all 32,926 protein-coding genes were used as anchors to extract surrounding genomic sequences with a fixed window size of $\pm 9 \mathrm{bp}$. Consensus sequence logos of all extracted donor and acceptor sites were created using $\mathrm{R}$ and the package ggseqlogo 66,67 .

\section{Codon usage bias among different species}

Synonymous codon usage biases in P. patens, S. frugiperda, H. sapiens, C. griseus, $O$. sativa, and $N$. tabacum were obtained from the Codon Usage Database (https://www.kazusa.or.jp/codon/) and biased codons in moss were compared with the codon usage pattern of other species.

\section{Confocal microscopy imaging and image analysis}

All images were taken with a Leica TCS SP8 microscope (Leica Microsystems, Wetzlar, Germany) using HCX PL APO 63x/1.40 oil objective with a zoom factor of 4.5 . For the excitation of Citrine, an WL laser was applied at $2 \%$ with an excitation wavelength of $514 \mathrm{~nm}$. The voxel sizes were $0.080 \mu \mathrm{m}$ on the $X-Y$ dimensions and $0.300 \mu \mathrm{m}$ on the $Z$ dimension. The pinhole was adjusted to 1 Airy Unit $(95.5 \mu \mathrm{m})$.

The image processing consists of the following steps: i) denoising, ii) edge enhancement, iii) Richardson-Lucy restoration, iv) local intensity equalization, v) segmentation. In the first step, a median filter with a window of $(3,3,3)$ was applied to the images in order to remove the salt-andpepper noise. In the second step, the denoised images were subjected to an unsharp-mask operation ${ }^{68,69}$, which involves blurring the image with a Gaussian filter, subtracting the blurred image from the input image, and adding the resulting difference back to the input image, a process that sharpens the edges in the images. The edge-enhanced images were then subjected to the Richardson-Lucy restoration algorithm, as implemented in the scikit-image package ${ }^{70}$ for three iterations, assuming an averaging filter in a window of $(3,5,5)$ as point spread function (here the aim was to smooth the image without losing the thin structures, rather than a true deblurring). The code for the Richardson-Lucy algorithm was adapted from scikit-image package ${ }^{70}$ using Python programming language. Subsequently, a spatial intensity equalization step was implemented on the images using a home-built algorithm. In short, each image was divided into boxes with dimensions of $(7,7,7)$ voxels. The voxel values within these boxes were rescaled by multiplying the values in each box with weights that are calculated based on the skewness value corresponding to the same box. This step corrected for the intensity gradients in the image in order to minimize the loss of some low-intensity foreground voxels. In the last step, the images were segmented by applying an adaptive thresholding method, where the thresholds were determined locally by applying Otsu's method to local windows of $(7,19,19)$ voxels throughout the image volume. The code for the adaptive Otsu thresholding algorithm was developed based on the Otsu threshold function of the scikit-image package ${ }^{70}$ and the Numba package ${ }^{71}$. To suppress over-segmentation of noisy background areas, a low global threshold was also applied by first calculating Otsu's threshold for whole image and multiplying it with 0.66 . The adaptive thresholding operation yielded the binary masks that specified the foreground voxels, which in turn were used to calculate the mean voxel intensity for each original image. Three replicates were used for analysis of each of the FIX-Citrine and optiFIX-Citrine constructs. The same is true for FHCitrine and optiFH-Citrine but the quantification was not possible due to undetectable/very low signals in FH-Citrine images. All six FIX images were processed and quantified in a single run of a Python script by using the exact same parameters to avoid any possible bias. Other packages used to develop the code are: NumPy ${ }^{70,72}$, Pandas ${ }^{73}$ and SciPy ${ }^{74}$. The code used for the image processing and quantification can be obtained from www.plant-biotech.uni-freiburg.de. The procedure is shown in Supplementary Fig. 6. 
bioRxiv preprint doi: https://doi.org/10.1101/2020.09.30.320721; this version posted October 1,2020 . The copyright holder for this preprint

\section{Recombinant protein extraction and detection}

Proteins from the culture supernatant were precipitated as described ${ }^{75}$. After air drying, the precipitate was resuspended in $50 \mathrm{mM}$ HEPES, $2 \%$ SDS ( $\mathrm{pH} \mathrm{7.5)} \mathrm{and} \mathrm{disulfide} \mathrm{bonds} \mathrm{within} \mathrm{proteins} \mathrm{were}$ reduced with $25 \mathrm{mM}$ dithiothreitol (DTT), followed by alkylation of the thiol groups with $60 \mathrm{mM}$ iodoacetamide (IAA). For Western blot analyses, 7.5\% SDS polyacrylamide gel electrophoresis (SDSPAGE Ready Gel ${ }^{\circledR}$ Tris-HCl Precast Gels, BioRad, CA, USA) was run at $100 \mathrm{~V}$ for $1 \mathrm{~h} 30 \mathrm{~min}$ and blotted to polyvinylidene fluoride (PVDF) membranes (Amersham Hybond P $0.45 \mu \mathrm{m}$ pore size PVDF blotting membrane, GE Healthcare) in a Trans-Blot ${ }^{\circledR}$ SD Semi-Dry Transfer Cell (BioRad) for $2 \mathrm{~h}$ with $1.8 \mathrm{~mA} / \mathrm{cm}^{2}$ membrane. The membrane was blocked for $1 \mathrm{~h}$ at room temperature in TBS containing 4\% Amersham ECL Prime Blocking Reagent (GE Healthcare) and 0.1\% Tween 20. It was then incubated with polyclonal anti-factor IX antibody (F0652, SIGMA) (1:3000) overnight at $4^{\circ} \mathrm{C}$. Afterwards, the membrane was washed three times with TBS containing $0.1 \%$ Tween 20 and incubated with horseradish peroxidase-linked anti-rabbit IgG (NA934, GE Healthcare) at a dilution of 1:10,000 for $1 \mathrm{~h}$. The blot was washed again and proteins were detected using the Amersham ECL Prime Western Blotting Detection Reagent (GE Healthcare) according to the manufacturer's instructions.

\section{Sample preparation and MS analysis}

The reduced and alkylated protein extracts were subjected to SDS-PAGE. Appropriate gel bands showing FIX fractions were excised and processed for in-gel digestion: Following the destaining of the gel bands with $30 \%$ acetonitrile (ACN), they were treated with $100 \% \mathrm{ACN}$ and dried completely in a vacuum concentrator. Tryptic in-gel digestion of gel slices was performed overnight at $37^{\circ} \mathrm{C}$ in $50 \mathrm{mM}$ ammonium bicarbonate using $0.1 \mu \mathrm{g}$ trypsin (Promega) per gel band. Afterwards, peptides were extracted from the gel with $5 \%$ formic acid. Analyses were performed using the UltiMate 3000 RSLCnano system (Dionex LC Packings/Thermo Fisher Scientific) coupled online to a QExactive Plus instrument (Thermo Fisher Scientific). The UHPLC systems was equipped with a C18-precolumn (Ø: $0.3 \mathrm{~mm}, 5 \mathrm{~mm}$; PepMap, Thermo Fisher Scientific) and an Acclaim ${ }^{\circledR}$ PepMap analytical column (ID: 75 m, 500 mm, 2 m, 100 Å, Dionex LC Packings/Thermo Fisher Scientific).

MS analyses were performed using a binary solvent system consisting of $0.1 \%$ formic acid (FA, solvent A, "A") and $0.1 \% \mathrm{FA} / 86 \% \mathrm{ACN}$ (solvent B, "B"). Samples were washed and concentrated on a C18 pre-column with $0.1 \%$ TFA for 5 min before switching the column in line with the analytical column. Peptide separation was performed applying a 45 -min gradient at a flow rate of $250 \mathrm{nl} / \mathrm{min}$. Peptide samples were eluted with a gradient of $4-40 \%$ B in $30 \mathrm{~min}$ and $40-95 \%$ B in 5 min. After each gradient, the analytical column was washed with $95 \%$ B for 5 min and re-equilibrated for 15 min with $4 \% \mathrm{~B}$. The MS instrument was externally calibrated using standard compounds and equipped with a nanoelectrospray ion source and distal coated SilicaTips (FS360-20-10-D, New Objective, Woburn, MA, USA), and MS/MS analyses were performed on multiply charged peptide ions. The measurement was performed using UltiMate 3,000 RSLCnano system (Dionex LC Packings/Thermo Fisher Scientific, Dreieich, Germany) coupled online to a QExactive Plus mass spectrometer (Thermo Fisher Scientific, Bremen, Germany) and mass spectrometer was operated in the data-dependent mode to automatically switch between MS (max. of $1 \times 10$ ions) and MS/MS. Each MS scan was followed by a maximum of $12 \mathrm{MS} / \mathrm{MS}$ scans using HCD with a normalized collision energy of $35 \%$. The mass range for MS was $\mathrm{m} / \mathrm{z}=375-1,700$ and resolution was set to 70,000 . MS parameters were as follows: spray voltage $1.5 \mathrm{kV}$; ion transfer tube temperature $200^{\circ} \mathrm{C}$. Raw data were analyzed using Mascot Distiller V2.5.1.0 (Matrix Science, USA) and the peak lists were searched with Mascot V2.6.0 against an inhouse database containing all $P$. patens V1.6 protein models ${ }^{22}$ as well as human FIX (complete and alternative ones based on splicing). The peptide mass tolerance was set to $8 \mathrm{ppm}$ and the fragment mass tolerance was set to $0.02 \mathrm{Da}$. carbamidomethylation $(\mathrm{C},+57.021464 \mathrm{Da})$ was specified as fixed 
modification. Variable modifications were Gln->pyro-Glu (-17.026549 Da), oxidation/hydroxylation (M, $\mathrm{P},+15.994915 \mathrm{Da})$ and deamidation $(\mathrm{N},+0.984016 \mathrm{Da})$. A total of two missed cleavages was allowed as well as semitryptic peptides. Search results were loaded into Scaffold4 software (Version 4.11.0, Proteome Software Inc., Portland, OR) and an additional database search using X!Tandem ${ }^{76}$ implemented in the software on the loaded spectra was performed.

\section{ACKNOWLEDGEMENTS}

We thank Bettina Warscheid for the possibility to use the QExactive Plus mass spectrometer and Anne Katrin Prowse for language editing. This work was supported by the Excellence Initiative of the German Federal and State Governments (GSC-4 to O.T., EXC-294 and EXC-2193/1 - 390951807 to R.R.); and a grant from the German Federal Ministry of Education and Research (BMBF 0313852C to R.R.).

\section{AUTHOR CONTRIBUTIONS}

O.T., E.L.D. and R.R. designed research; O.T., S.W.L.M., B.Ö., and N.v.G. performed research and together with S.N.W.H analyzed data; O.T., E.L.D., and R.R. wrote the paper.

\section{DATA AVAILABILITY}

All data generated or analyzed during this study are included in this article and its supplementary information.

\section{CODE AVAILABILITY}

JavaScript-based web application, physCO, as well as the code used for the image processing and quantification are available at www.plant-biotech.uni-freiburg.de.

\section{COMPETING INTERESTS}

The authors are inventors of patents and patent applications related to the production of recombinant proteins. R.R. is a founder of Greenovation Biotech (now eleva). He currently serves as advisory board member of this company. Eleva develops and markets moss-based biopharmaceuticals. 


\section{REFERENCES}

1. Sakharkar, M. K., Chow, V. T. K. \& Kangueane, P. Distributions of exons and introns in the human genome. In Silico Biol. 4, 387-393 (2004).

2. Georgomanolis, T., Sofiadis, K. \& Papantonis, A. Cutting a long intron short: Recursive splicing and its implications. Front. Physiol. 7, 598 (2016).

3. Rogozin, I. B., Carmel, L., Csuros, M. \& Koonin, E. V. Origin and evolution of spliceosomal introns. Biology Direct 7, 11 (2012).

4. Papasaikas, P. \& Valcárcel, J. The spliceosome: The ultimate RNA chaperone and sculptor. Trends in Biochemical Sci. 41(1), 33-45 (2016).

5. Berget, S. M. Exon recognition in vertebrate splicing. J. of Biol. Chem. 270, 2411-2414 (1995).

6. Goldstrohm, A. C., Greenleaf, A. L. \& Garcia-Blanco, M. A. Co-transcriptional splicing of premessenger RNAs: Considerations for the mechanism of alternative splicing. Gene 277, 31-47 (2001).

7. Dredge, B. K., Polydorides, A. D. \& Darnell, R. B. The splice of life: Alternative splicing and neurological disease. Nat. Rev. Neurosci. 2, 43-50 (2001).

8. Shai, O., Morris, Q. D., Blencowe, B. J. \& Frey, B. J. Inferring global levels of alternative splicing isoforms using a generative model of microarray data. Bioinformatics 22, 606-613 (2006).

9. Nissim-Rafinia, M. \& Kerem, B. Splicing regulation as a potential genetic modifier. Trends in Genetics 18(3), 123-127 (2002).

10. Yu, J. et al. Minimal introns are not 'junk'. Genome Res. 12, 1185-1189 (2002).

11. Nilsen, T. W. \& Graveley, B. R. Expansion of the eukaryotic proteome by alternative splicing. Nature 463, 457-463 (2010).

12. Sanchez, L. \& Sánchez, L. Sex-determining mechanisms in insects. Int. J. Dev. Biol. 52, 837856 (2008).

13. Shang, X., Cao, Y. \& Ma, L. Alternative splicing in plant genes: A means of regulating the environmental fitness of plants. Int. J. Mol. Sci. 18, 432 (2017).

14. Deckert, J. et al. Protein composition and electron microscopy structure of affinity-purified human spliceosomal B complexes isolated under physiological conditions. Mol. Cell. Biol. 26, 5528-5543 (2006).

15. Amit, M. et al. Differential GC content between exons and introns establishes distinct strategies of splice-site recognition. Cell Rep. 1, 543-556 (2012).

16. Carmel, I., Tal, S., Vig, I. \& Ast, G. Comparative analysis detects dependencies among the $5^{\prime}$ splice-site positions. RNA 10, 828-840 (2004).

17. Chiara, M. D., Palandjian, L., Kramer, R. F. \& Reed, R. Evidence that U5 snRNP recognizes the 3' splice site for catalytic step II in mammals. EMBO J. 16, 4746-4759 (1997).

18. Hall, S. L. \& Padgett, R. A. Conserved sequences in a class of rare eukaryotic nuclear introns with non-consensus splice sites. J. Mol. Biol. 239, 357-365 (1994).

19. López, M. D., Alm Rosenblad, M. \& Samuelsson, T. Computational screen for spliceosomal RNA genes aids in defining the phylogenetic distribution of major and minor spliceosomal components. Nucleic Acids Res. 36, 3001-3010 (2008). 
bioRxiv preprint doi: https://doi.org/10.1101/2020.09.30.320721; this version posted October 1 , 2020. The copyright holder for this preprint (which was not certified by peer review) is the author/funder, who has granted bioRxiv a license to display the preprint in perpetuity. It is made available under aCC-BY-NC-ND 4.0 International license.

20. Syed, N. H., Kalyna, M., Marquez, Y., Barta, A. \& Brown, J. W. S. Alternative splicing in plants coming of age. Trends in Plant Sci. 17, 616-623 (2012).

21. Pan, Q., Shai, O., Lee, L. J., Frey, B. J. \& Blencowe, B. J. Deep surveying of alternative splicing complexity in the human transcriptome by high-throughput sequencing. Nat. Genet. 40, 1413-1415 (2008).

22. Zimmer, A. D. et al. Reannotation and extended community resources for the genome of the non-seed plant Physcomitrella patens provide insights into the evolution of plant gene structures and functions. BMC Genomics 14, 498 (2013).

23. Lloyd, J. P. B. et al. The loss of SMG1 causes defects in quality control pathways in Physcomitrella patens. Nucleic Acids Res. 46, 5822-5836 (2018).

24. Melo, J. P., Kalyna, M. \& Duque, P. Current challenges in studying alternative splicing in plants: The case of Physcomitrella patens SR Proteins. Front. Plant Sci. 11, 286 (2020).

25. Schellenberg, M. J., Ritchie, D. B. \& MacMillan, A. M. Pre-mRNA splicing: A complex picture in higher definition. Trends in Biochemical Sciences 33, 243-246 (2008).

26. Maniatis, T. \& Reed, R. An extensive network of coupling among gene expression machines. Nature 416, 499-506 (2002).

27. Reed, R. Initial splice-site recognition and pairing during pre-mRNA splicing. Curr. Opin. Genet. Dev. 6, 215-220 (1996).

28. Ram, O. \& Ast, G. SR proteins: A foot on the exon before the transition from intron to exon definition. Trends in Genetics 23, 5-7 (2007).

29. Gelfman, S. et al. Changes in exon-intron structure during vertebrate evolution affect the splicing pattern of exons. Genome Res. 22, 35-50 (2012).

30. Haseloff, J., Siemering, K. R., Prasher, D. C. \& Hodge, S. Removal of a cryptic intron and subcellular localization of green fluorescent protein are required to mark transgenic Arabidopsis plants brightly. Proc. Natl. Acad. Sci. 94, 2122-2127 (1997).

31. Top, O., Geisen, U., Decker, E. L. \& Reski, R. Critical evaluation of strategies for the production of blood coagulation factors in plant-based systems. Front. Plant Sci. 10, 261 (2019).

32. S Schillberg, S., Raven, N., Spiegel, H., Rasche, S. \& Buntru, M. Critical analysis of the commercial potential of plants for the production of recombinant proteins. Front. Plant Sci. 10, 720 (2019).

33. Fischer, R. \& Buyel, J. F. Molecular farming - The slope of enlightenment. Biotechnology Advances 40, 107519 (2020).

34. Kurachi, K., Furukawa, M., Yao, S. N. \& Kurachi, S. Biology of factor IX. Hematol. Oncol. Clin. North Am. 6, 991-997 (1992).

35. Chen, C. X., Baker, J. R. \& Nichol, M. B. Economic burden of illness among persons with hemophilia $b$ from HUGS Vb: Examining the association of severity and treatment regimens with costs and annual bleed rates. Value Heal. 20, 1074-1082 (2017).

36. Decker, E. L. \& Reski, R. Mosses in biotechnology. Curr. Opin. Biotechnol. 61, 21-27 (2020).

37. Decker, E. L. \& Reski, R. Glycoprotein production in moss bioreactors. Plant Cell Rep. 31, 453460 (2012).

38. Hennermann, J. B. et al. Pharmacokinetics, pharmacodynamics, and safety of mossaGalactosidase A in patients with Fabry disease. J. Inherit. Metab. Dis. 42, 527-533 (2019). 
39. Reski, R., Parsons, J. \& Decker, E. L. Moss-made pharmaceuticals: From bench to bedside. Plant Biotechnol. J. 13, 1191-1198 (2015).

40. Michelfelder, S. et al. Moss-produced, glycosylation-optimized human factor $\mathrm{h}$ for therapeutic application in complement disorders. J. Am. Soc. Nephrol. 28, 1462-1474 (2017).

41. Top, O. et al. Recombinant Production of MFHR1, a novel synthetic multitarget complement inhibitor, in moss bioreactors. Front. Plant Sci. 10, 260 (2019).

42. Schaaf, A., Reski, R. \& Decker, E. L. A novel aspartic proteinase is targeted to the secretory pathway and to the vacuole in the moss Physcomitrella patens. Eur. J. Cell Biol. 83, 145-152 (2004).

43. Pucker, B. \& Brockington, S. F. Genome-wide analyses supported by RNA-Seq reveal noncanonical splice sites in plant genomes. BMC Genomics 19, 980 (2018).

44. Gitzinger, M., Parsons, J., Reski, R. \& Fussenegger, M. Functional cross-kingdom conservation of mammalian and moss (Physcomitrella patens) transcription, translation and secretion machineries. Plant Biotechnol. J. 7, 73-86 (2009).

45. Lang, D. et al. The Physcomitrella patens chromosome-scale assembly reveals moss genome structure and evolution. Plant J. 93, 515-533 (2018).

46. Rensing, S. A., Fritzowsky, D., Lang, D. \& Reski, R. Protein encoding genes in an ancient plant: Analysis of codon usage, retained genes and splice sites in a moss, Physcomitrella patens. BMC Genomics 6, 292 (2005).

47. Kalyna, M. et al. Alternative splicing and nonsense-mediated decay modulate expression of important regulatory genes in Arabidopsis. Nucleic Acids Res. 40, 2454-2469 (2012).

48. Drechsel, G. et al. Nonsense-mediated decay of alternative precursor mRNA splicing variants is a major determinant of the Arabidopsis steady state transcriptome. Plant Cell 25, 3726-3742 (2013).

49. Hiss, M. et al. Combination of the endogenous Ihcsr1 promoter and codon usage optimization boosts protein expression in the moss Physcomitrella patens. Front. Plant Sci. 8, 1842 (2017).

50. Nakamura, Y., Gojobori, T. \& Ikemura, T. Codon usage tabulated from international DNA sequence databases: status for the year 2000. Nucleic Acids Res. 28, 292 (2000).

51. Latijnhouwers, M. J., Pairoba, C. F., Brendel, V., Walbot, V. \& Carle-Urioste, J. C. Test of the combinatorial model of intron recognition in a native maize gene. Plant Mol. Biol. 41, 637-644 (1999).

52. Szcześniak, M. W., Kabza, M., Pokrzywa, R., Gudyś, A. \& Makalowska, I. ERISdb: A database of plant splice sites and splicing signals. Plant Cell Physiol. 54, e10 (2013).

53. Reddy, A. S. N. Alternative splicing of pre-messenger RNAs in plants in the genomic era. Annu. Rev. Plant Biol. 58, 267-294 (2007).

54. Lander, E. S. et al. Initial sequencing and analysis of the human genome. Nature 409, 860-921 (2001).

55. Duret, L., Mouchiroud, D. \& Gautier, C. Statistical analysis of vertebrate sequences reveals that long genes are scarce in GC-rich isochores. J. Mol. Evol. 40, 308-317 (1995).

56. Kong, A. et al. A high-resolution recombination map of the human genome. Nat. Genet. 31 241-247 (2002).

57. Kudla, G., Lipinski, L., Caffin, F., Helwak, A. \& Zylicz, M. High guanine and cytosine content increases mRNA levels in mammalian cells. PLoS Biol. 4(6), e180 (2006). 
58. Meunier, J. \& Duret, L. Recombination drives the evolution of GC-content in the human genome. Mol. Biol. Evol. 21, 984-990 (2004).

59. Carels, N. \& Bernardi, G. Two classes of genes in plants. Genetics 154, 1819-1825 (2000).

60. Weise, A. et al. Use of Physcomitrella patens actin 5' regions for high transgene expression: Importance of 5' introns. Appl. Microbiol. Biotechnol. 70, 337-345 (2006).

61. Koprivova, A. et al. Targeted knockouts of Physcomitrella lacking plant-specific immunogenic N-glycans. Plant Biotechnol. J. 2, 517-523 (2004).

62. Frank, W., Decker, E. L. \& Reski, R. Molecular tools to study Physcomitrella patens. Plant Biol. (Stuttg) 7, 220-227 (2005).

63. Strepp, R., Scholz, S., Kruse, S., Speth, V. \& Reski, R. Plant nuclear gene knockout reveals a role in plastid division for the homolog of the bacterial cell division protein FtsZ, an ancestral tubulin. Proc. Natl. Acad. Sci. 95, 4368-4373 (1998).

64. Decker, E. L., Wiedemann, G. \& Reski, R. Gene targeting for precision glyco-engineering: Production of biopharmaceuticals devoid of plant-typical glycosylation in moss bioreactors. in Glyco-Engineering: Methods and Protocols 213-224 (2015).

65. Schween, G., Fleig, S. \& Reski, R. High-throughput-PCR screen of 15,000 transgenic Physcomitrella plants. Plant Mol. Biol. Report. 160, 209-212 (2002).

66. R Development CoreTeam (2017) R: A language and environment for statistical computing. R Foundation for Statistical Computing, Vienna, Austria

67. Wagih, O. Ggseqlogo: A versatile R package for drawing sequence logos. Bioinformatics 33, 3645-3647 (2017).

68. Maack, I. \& Neitzel, U. Optimized image processing for routine digital radiography. in Computer Assisted Radiology / Computergestützte Radiologie (eds. Lemke, H. U., Rhodes, M. L., Jaffe, C. C. \& Felix, R.) 109-114 (Springer Berlin Heidelberg, 1991).

69. Critchley, H. D. et al. Human cingulate cortex and autonomic control: Converging neuroimaging and clinical evidence. Brain 126, 2139-2152 (2003).

70. van der Walt, S. et al. scikit-image: image processing in Python. PeerJ 2, e453 (2014).

71. Lam, S. K., Pitrou, A. \& Seibert, S. Numba. in Proceedings of the Second Workshop on the LLVM Compiler Infrastructure in HPC - LLVM '15 1-6 (ACM Press, 2015).

72. Oliphant, T. \& Millma, J. k. A guide to NumPy. Trelgol Publishing (2006).

73. McKinney, W. Data Structures for Statistical Computing in Python. Proc. 9th Python Sci. Conf. (2010).

74. Virtanen, P. et al. SciPy 1.0: fundamental algorithms for scientific computing in Python. Nat. Methods (2020).

75. Hoernstein, S. N. W. et al. Host cell proteome of Physcomitrella patens harbors proteases and protease inhibitors under bioproduction conditions. J. Proteome Res. 17, 3749-3760 (2018).

76. Craig, R., and Beavis, R. C. A method for reducing the time required to match protein sequences with tandem mass spectra. Rapid Commun. Mass Spectrom. 17, 2310-2316 (2003). 


\section{FIGURES AND FIGURE LEGENDS}

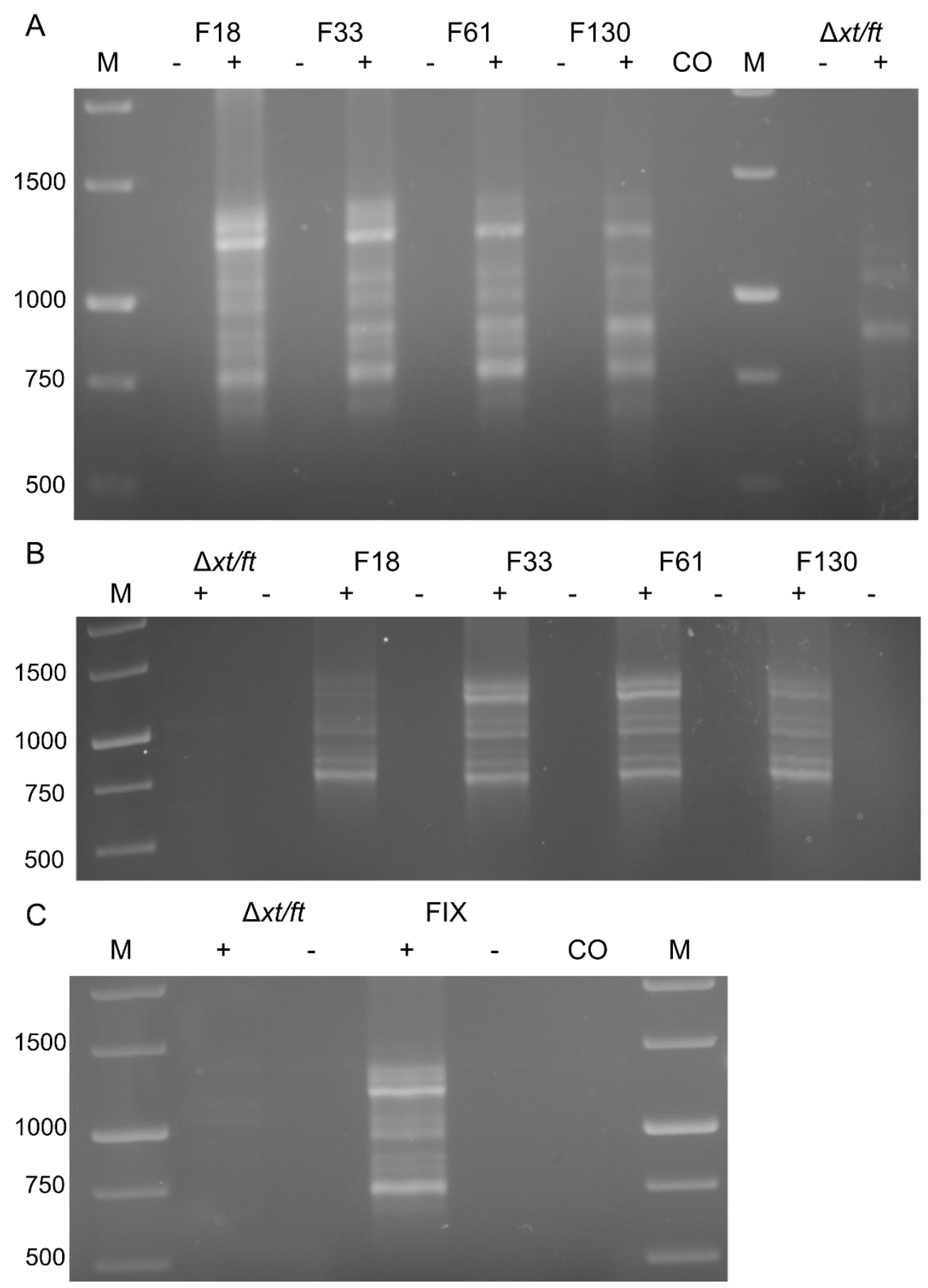

Fig. 1: Expression of FIX in Physcomitrella patens. a Total RNA from protonema cultures of 4 FIXtransgenic lines $(F)$ and the parental line $\Delta x t / f t$ was prepared and used for RT-PCR using the primers FIXfwdB and FIXrevB. b RT-PCR of FIX using the primers FIXfwdB and FIXrevB from gametophores of the same lines. C RT-PCR of FIX with mRNA extracted from transiently transfected (FIX) as well as non-transfected $(\Delta x t / f t)$ cells. M: $1 \mathrm{~kb}$ Marker (Thermo Fisher Scientific), -: without reverse transcription, +: with reverse transcription, $\mathrm{CO}$ : Water control. 
A

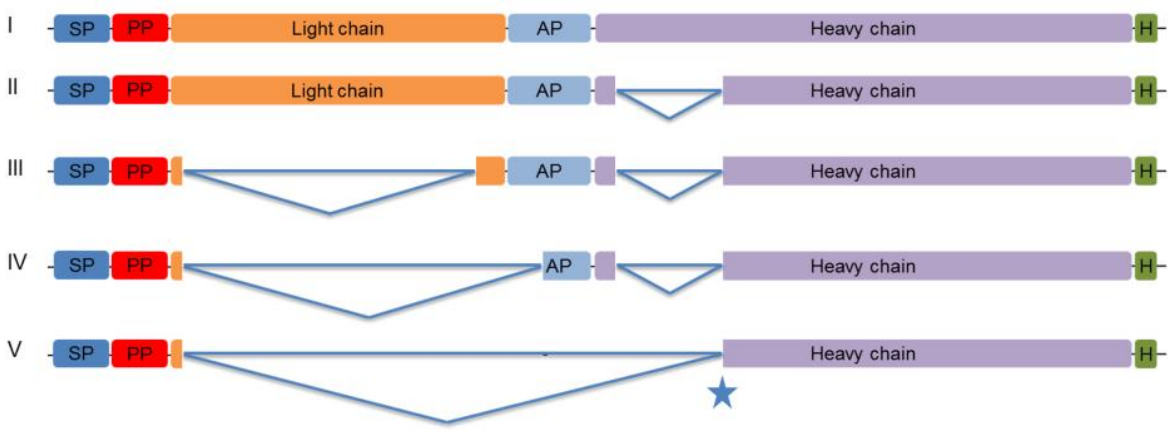

B

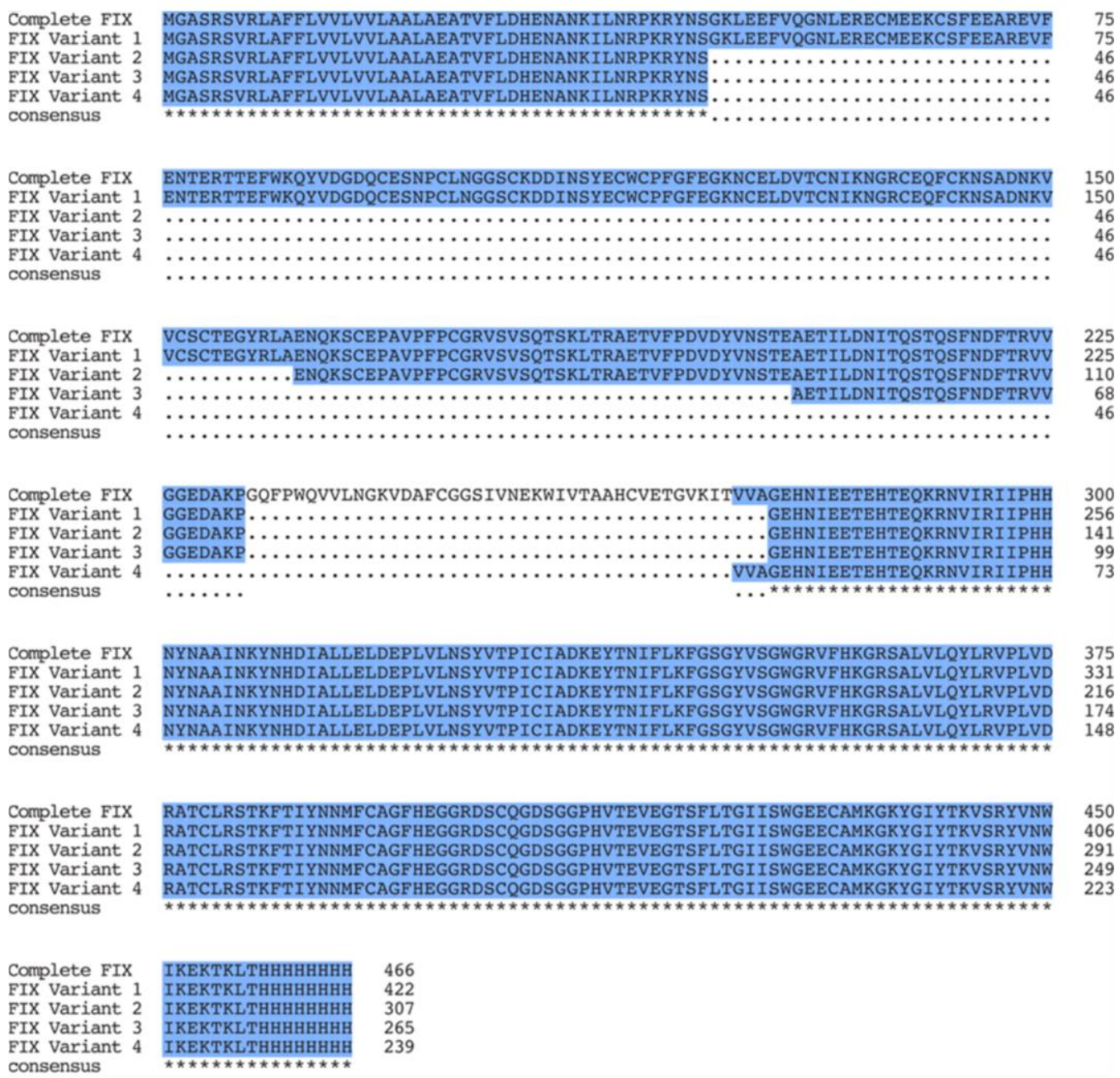

Fig. 2: Schematic representation of FIX transcripts and multiple sequence alignment of predicted FIX protein isoforms based on experimentally verified transcripts detected in Physcomitrella patens. a Full-length FIX transcript (a.i), FIX variant with the deletion of a 44 aa long domain in the CDS for the heavy chain (a.ii), FIX variant with deletions in the CDS for both light and heavy chain (a.iii), FIX variant with deletions in the CDS for light chain, activation peptide and heavy chain (a.iv), FIX variant missing the CDS completely for the activation peptide, nearly full-length of light chain and 41 aa long domain in the heavy chain (a.v). The star indicates the usage of a donor site 9 bp earlier than previously identified donor site in the heavy chain. SP: PpAP1 signal peptide, PP: propeptide, AP: activation peptide, $\mathrm{H}$ : $8 \mathrm{x}$ His tag. b Alignment was performed and formatted for publication with MUSCLE via the "MSA" package for $\mathrm{R}^{49,50}$ 
A

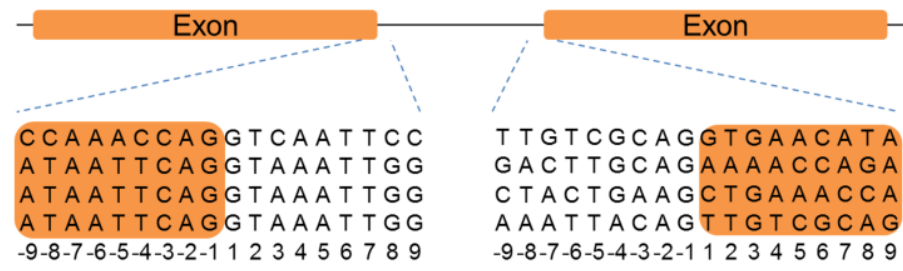

B
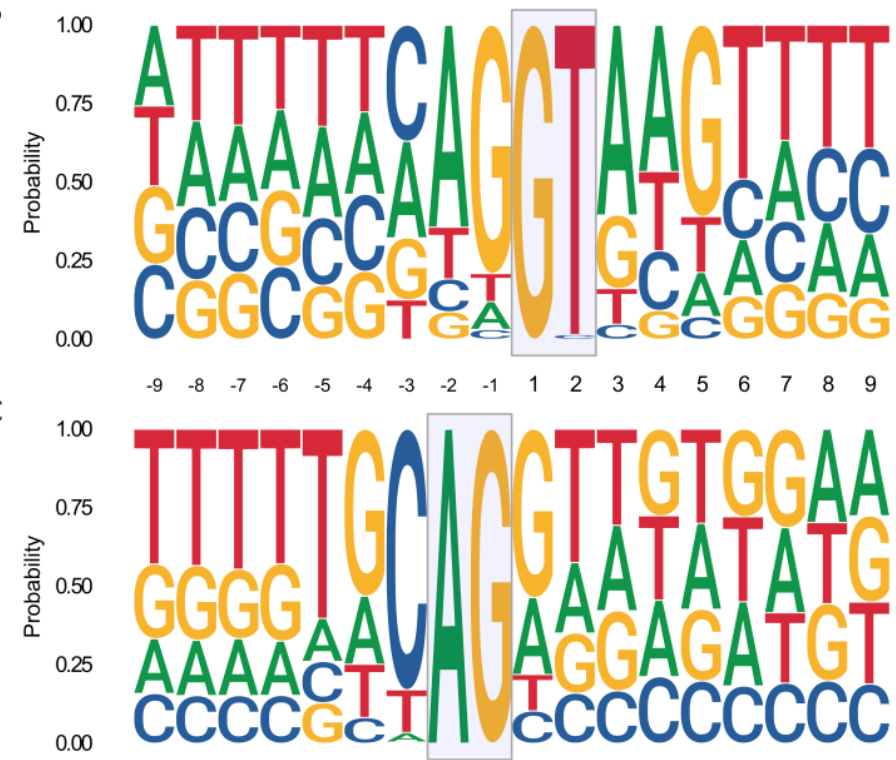

$\begin{array}{llllllllllllllllllllllllllllllll}-9 & -8 & -7 & -6 & -5 & -4 & -3 & -2 & -1 & 1 & 2 & 3 & 4 & 5 & 6 & 7 & 8 & 9\end{array}$

Fig. 3: Schematic representation of donor and acceptor sites within the FIX sequence and consensus sequence motifs of donor and acceptor splice sites recovered from all 87,533 $P$. patens transcripts. a Donor and acceptor sites. Four different splicing motifs were identified after sequencing FIX variants. Left side shows donor site and right side shows acceptor site. "-1" represents last nucleotide of exon in the donor site (left side) or last nucleotide of intron in the acceptor site (right side). b, c Consensus genomic sequence motifs of donor (b) and acceptor splice sites (c) extracted from all 32,926 $P$. patens protein-coding genes. Probability and height of individual letters correspond to base frequencies at each position. 


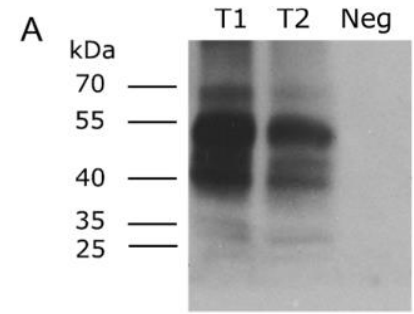

B

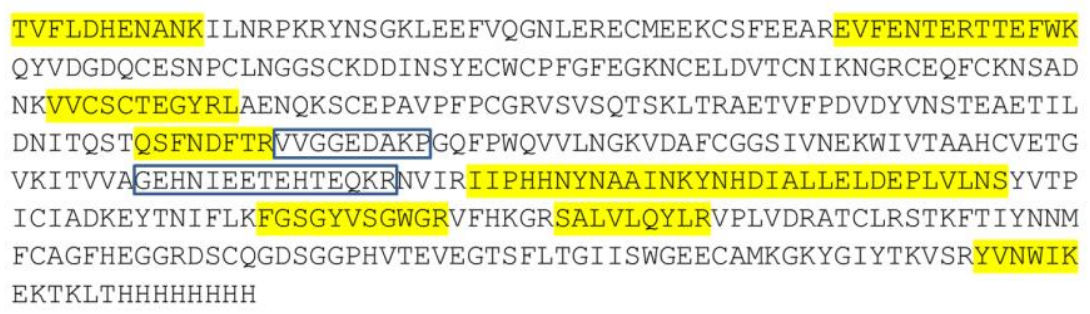

Fig. 4: Analysis on moss-produced FIX protein isoforms. a Immunodetection of extracellular FIX produced by two transfections (anti-FIX Ab 1:5,000). Culture supernatant of non-transfected cells was used as negative control (Neg). T1, T2: Two different transient transfections with the FIX cDNA-based expression plasmid. b Full-length mossFIX amino acid sequence. Amino acids marked in yellow were identified in the MS analysis. Blue boxes mark the parts of the peptide VVGGEDAKPGEHNIEETEHTEQKR which was identified in MS analysis and represents a heterosplice product. 
A

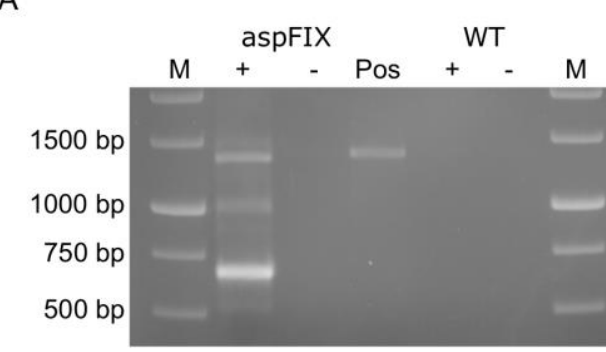

B

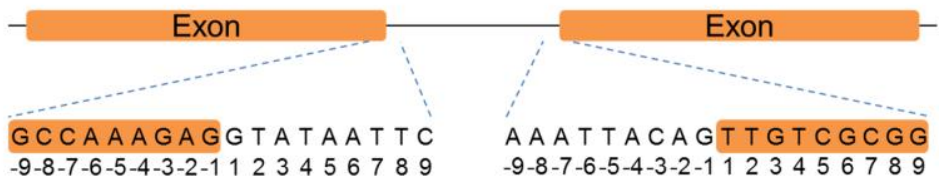

C

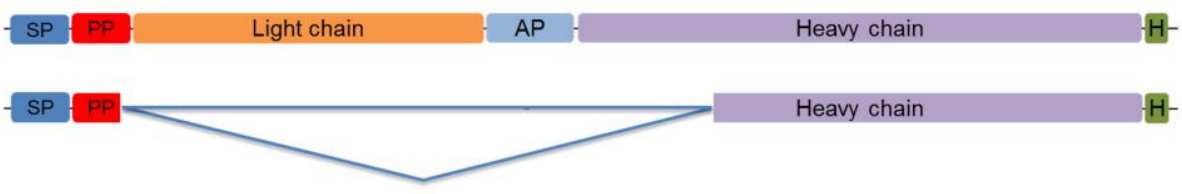

D

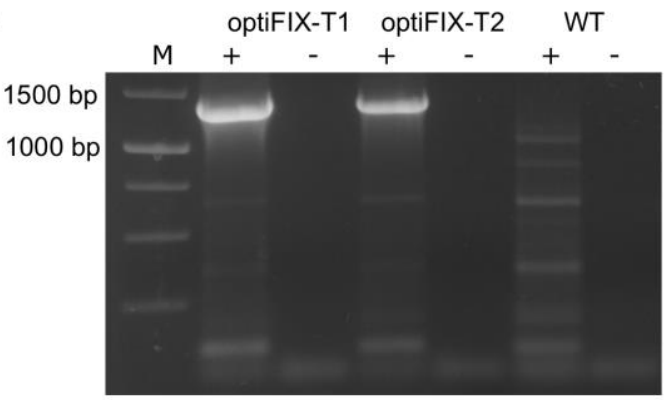

E T1 T2 Neg

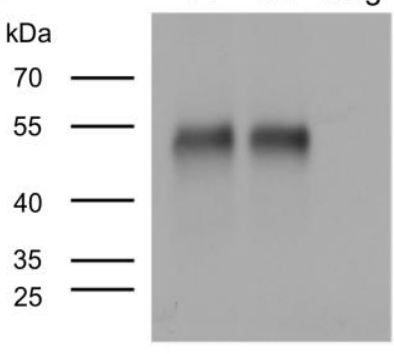

Fig. 5: Heterosplicing of the human FIX CDS in Physcomitrella patens was successfully prevented by codon optimization. a RT-PCR of FIX RNA from cells that were transiently transfected with aspFIX and non-transfected cells (WT). M: $1 \mathrm{~kb}$ Marker (Thermo Fisher Scientific), -: without reverse transcription, +: with reverse transcription, Pos: PCR with aspFIX plasmid used as positive control. b Splicing motifs identified after sequencing the FIX variant. The left side shows the donor site and the right side the acceptor site. "-1" represents the last nucleotide of the exon at the donor site or the intron at the acceptor site, respectively. c Schematic representation of complete FIX (upper) and the additional variant (lower). SP: signal peptide, PP: propeptide, AP: activation peptide. d RT-PCR of FIX RNA from cells that were transiently transfected with optiFIX and non-transfected cells (WT), respectively. e Immunodetection of extracellular FIX protein with anti-FIX Ab $(1: 5,000)$. Culture supernatant of non-transfected cells was used as negative control (Neg). T1, T2: Two different transient transfections with the optiFIX plasmid. M: 1 kb Marker (Thermo Fisher Scientific). 

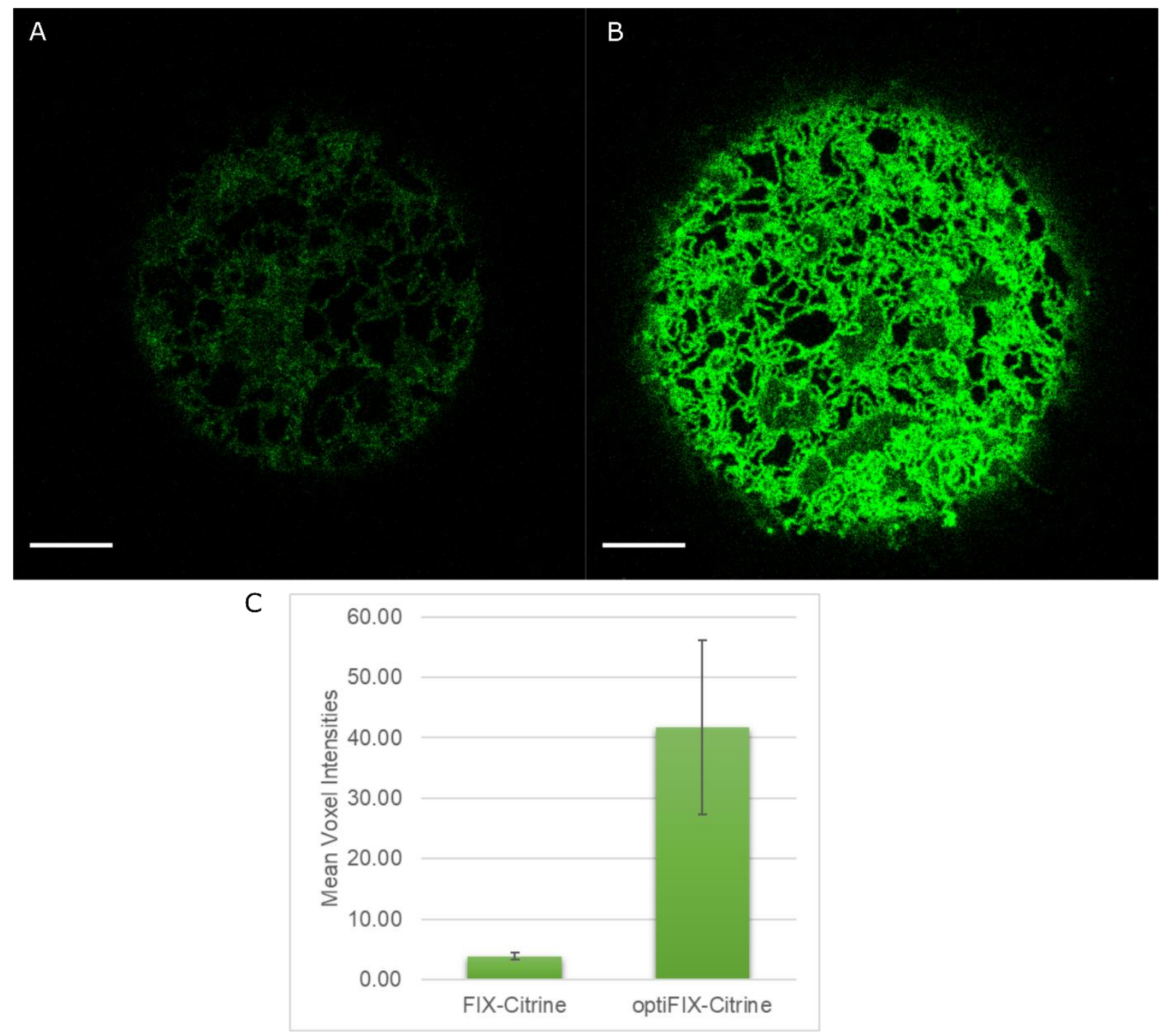

Fig. 6: Comparison of FIX and optiFIX protein levels using confocal microscopy and quantitative image analysis. a Transient overexpression of FIX-Citrine. The slice with the brightest mean intensity was extracted from a Z-stack and its voxel intensity range was adjusted to (0-36) for illustration. Scale bar is $5 \mu \mathrm{m}$. b Transient overexpression of optiFIX-Citrine. The slice with the brightest mean intensity was extracted from a Z-stack and its voxel intensity range was adjusted to (036) for illustration. Scale bar is $5 \mu \mathrm{m}$. c Comparison of the mean signal intensities of the Z-stacks for FIX-Citrine and optiFIX-Citrine $(n=3)$. 
bioRxiv preprint doi: https://doi org/10.1101/2020.09.30.320721; this version posted October 1, 2020. The copyright holder for this preprint (which was not certified by peer review) is the author/funder, who has granted bioRxiv a license to display the preprint in perpetuity. It is made available under aCC-BY-NC-ND 4.0 International license.
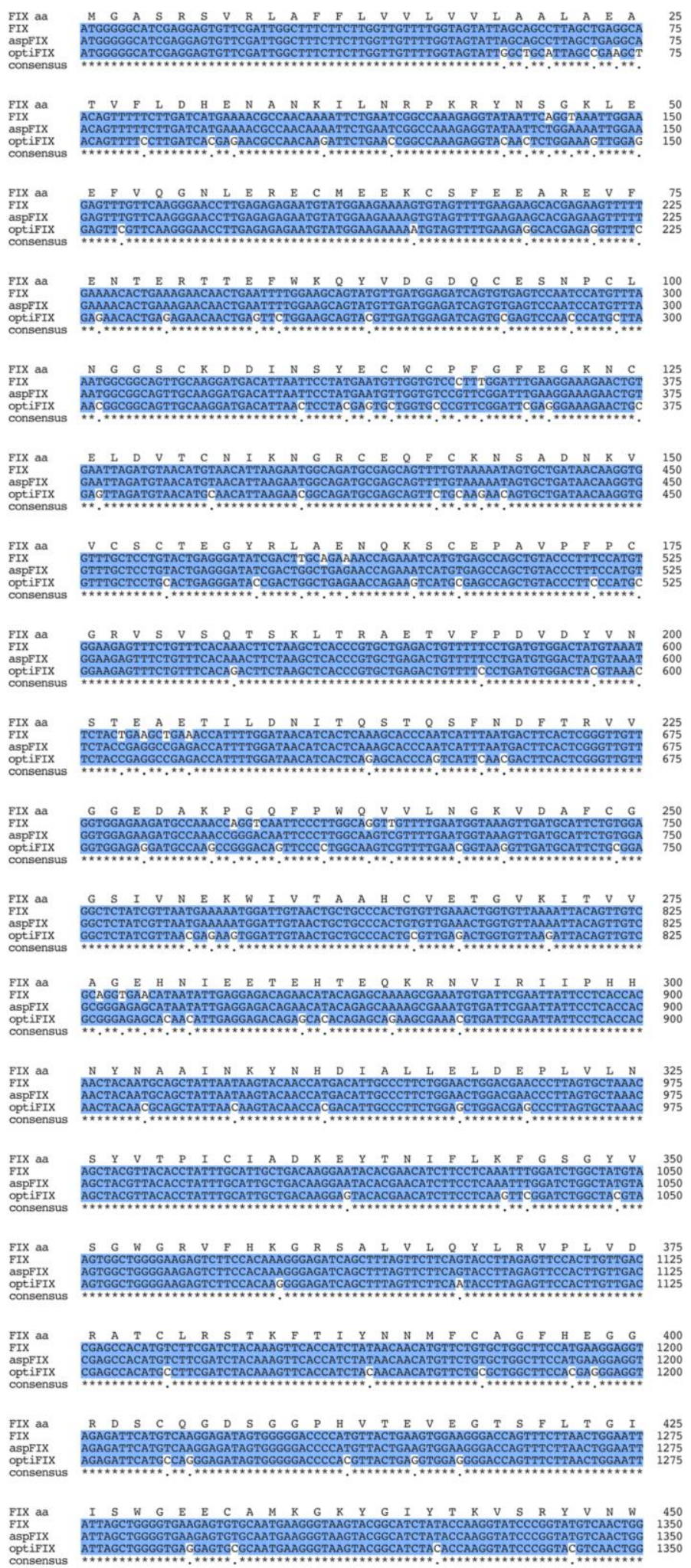

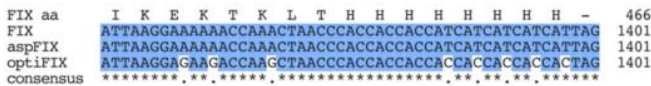

Fig. 7: Multiple sequence alignment of FIX, aspFIX and optiFIX CDS. The translated amino acid sequence of FIX (FIX aa) was added for better visualization. Alignment was performed and formatted for publication with MUSCLE via the "MSA" package for $\mathrm{R}^{49,50}$. 


\section{TABLES AND THEIR LEGENDS}

Table 1: The codon usage frequencies of under- and over-represented codons for eight amino acids in different protein expression systems. Numbers represent the frequency of codon per thousand. Data are from http://www.kazusa.or.jp/codon/.

\begin{tabular}{|c|c|c|c|c|c|c|c|c|}
\hline & & $\begin{array}{l}\text { Physcomitrella } \\
\text { patens }\end{array}$ & $\begin{array}{l}\text { Spodoptera } \\
\text { frugiperda }\end{array}$ & $\begin{array}{l}\text { Homo sapiens } \\
\text { (HEK cells) }\end{array}$ & $\begin{array}{l}\text { Cricetulus griseus } \\
\text { (CHO cells) }\end{array}$ & Oryza sativa & $\begin{array}{l}\text { Nicotiana } \\
\text { tabacum }\end{array}$ & \\
\hline $\begin{array}{l}\text { under- } \\
\text { represented }\end{array}$ & TGT & 7.0 & 8.5 & 10.6 & 9.1 & 6.2 & 9.8 & \multirow{2}{*}{ Cys } \\
\hline $\begin{array}{l}\text { over- } \\
\text { represented }\end{array}$ & TGC & 9.8 & 13.2 & 12.6 & 10.3 & 12.4 & 7.2 & \\
\hline $\begin{array}{l}\text { under- } \\
\text { represented }\end{array}$ & GAA & 24.1 & 27.6 & 29.0 & 28.4 & 21.6 & 36.0 & \multirow{2}{*}{ Glu } \\
\hline $\begin{array}{l}\text { over- } \\
\text { represented }\end{array}$ & GAG & 37.4 & 33.1 & 39.6 & 41.1 & 38.6 & 29.4 & \\
\hline $\begin{array}{l}\text { under- } \\
\text { represented }\end{array}$ & TTT & 17.2 & 10.1 & 17.6 & 19.6 & 13.1 & 25.1 & \multirow{2}{*}{ Phe } \\
\hline $\begin{array}{l}\text { over- } \\
\text { represented }\end{array}$ & TTC & 23.6 & 27.5 & 20.3 & 22.0 & 22.4 & 18.0 & \\
\hline $\begin{array}{l}\text { under- } \\
\text { represented }\end{array}$ & CAT & 11.1 & 8.7 & 10.9 & 10.2 & 11.3 & 13.4 & \multirow{2}{*}{ His } \\
\hline $\begin{array}{l}\text { over- } \\
\text { represented }\end{array}$ & CAC & 11.6 & 15.6 & 15.1 & 12.9 & 13.8 & 8.7 & \\
\hline $\begin{array}{l}\text { under- } \\
\text { represented }\end{array}$ & AAA & 18.9 & 26.8 & 24.4 & 24.6 & 16.0 & 32.6 & \multirow{2}{*}{ Lys } \\
\hline $\begin{array}{l}\text { over- } \\
\text { represented }\end{array}$ & AAG & 34.7 & 49.2 & 31.9 & 38.4 & 32.3 & 33.5 & \\
\hline $\begin{array}{l}\text { under- } \\
\text { represented }\end{array}$ & AAT & 17.8 & 13.4 & 17.0 & 17.4 & 15.1 & 28.0 & \multirow{2}{*}{ Asn } \\
\hline $\begin{array}{l}\text { over- } \\
\text { represented }\end{array}$ & AAC & 20.4 & 28.8 & 19.1 & 21.2 & 18.5 & 17.9 & \\
\hline $\begin{array}{l}\text { under- } \\
\text { represented }\end{array}$ & CAA & 16.7 & 16.1 & 12.3 & 10.3 & 13.5 & 20.7 & \multirow{2}{*}{ Gln } \\
\hline $\begin{array}{l}\text { over- } \\
\text { represented }\end{array}$ & CAG & 22.0 & 21.6 & 34.2 & 33.4 & 20.8 & 15.0 & \\
\hline $\begin{array}{l}\text { under- } \\
\text { represented }\end{array}$ & TAT & 10.5 & 10.0 & 12.2 & 13.1 & 10.0 & 17.8 & \multirow{2}{*}{ Tyr } \\
\hline $\begin{array}{c}\text { over- } \\
\text { represented }\end{array}$ & TAC & 17.2 & 24.4 & 15.3 & 16.4 & 15.1 & 13.5 & \\
\hline
\end{tabular}


Table 2: Under-represented codons were changed into the over-represented ones based on the codon usage tables ${ }^{49,50}$ to optimize FIX sequence using aspFIX as a template.

Amino acid Under-represented codons in aspFIX For optiFIX, changed into

\begin{tabular}{c|c|c}
\hline Cys & TGT & TGC \\
\hline Glu & GAA & GAG \\
\hline Phe & TTT & TTC \\
\hline His & CAT & CAC \\
\hline Lys & AAA & AAG \\
\hline Asn & AAT & AAC \\
\hline GIn & CAA & CAG \\
\hline Tyr & TAT & TAC \\
\hline
\end{tabular}




\section{Supplementary Data}

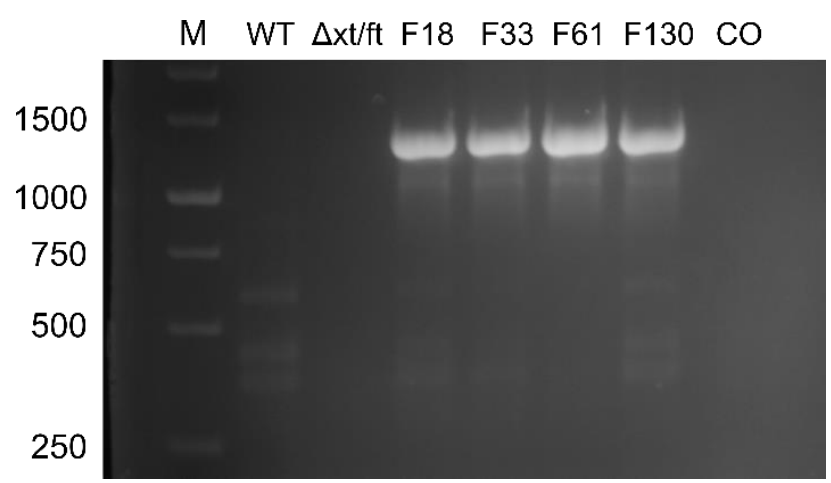

Supplementary Fig. 1: The presence of complete FIX CDS in transgenic lines. Genomic DNA from protonema cultures of $4 \mathrm{FIX}$-transgenic lines $(\mathrm{F})$, the parental line $\Delta x t / f t$, and WT was prepared and used for PCR using the primers FIXfwdB and FIXrevB. M: $1 \mathrm{~kb}$ Marker (Thermo Fisher Scientific), CO: Water control. 
A

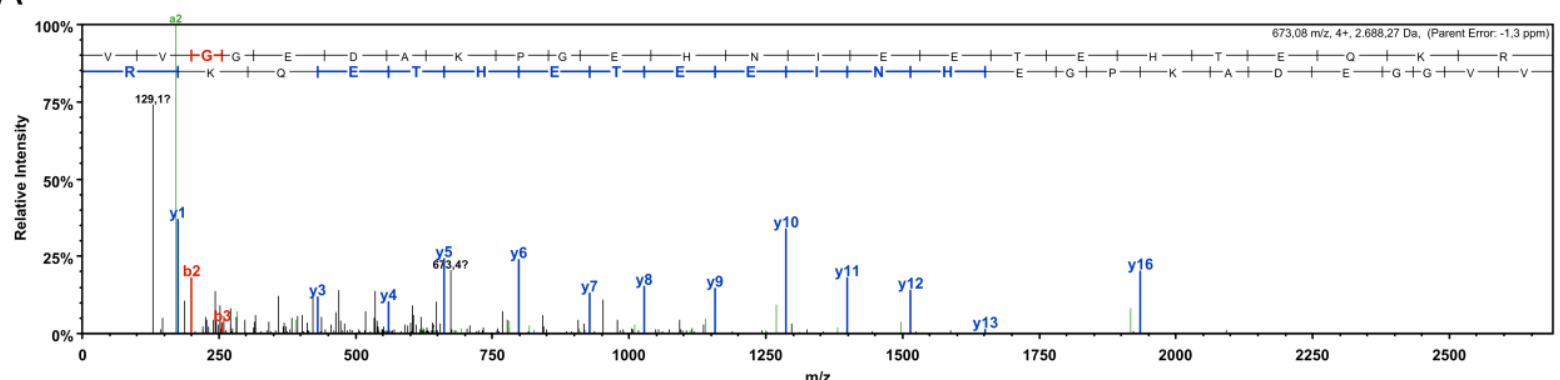

B

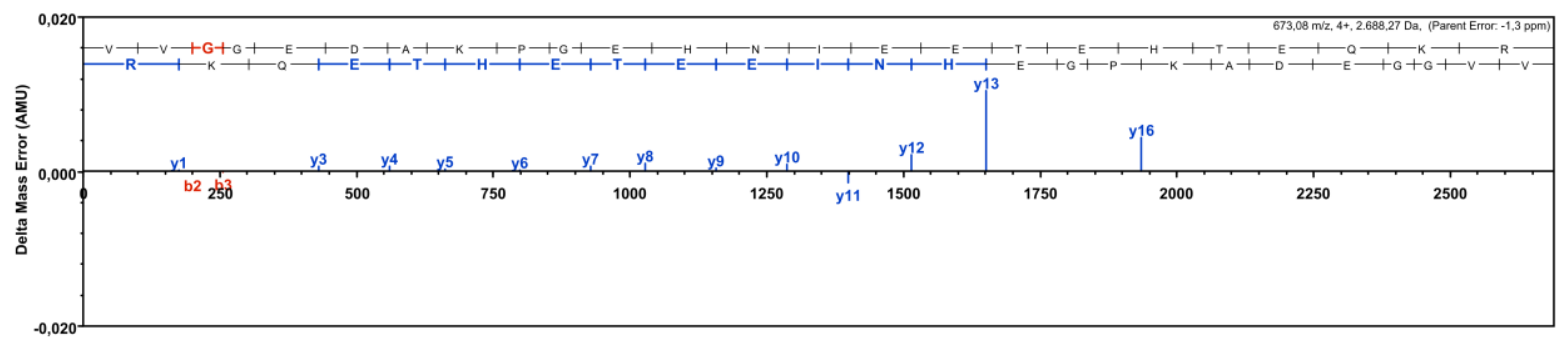

$\mathrm{m} / \mathrm{z}$

Supplementary Fig. 2: Identification of the peptide VVGGEDAKPGEHNIEETEHTEQKR by MS. a HCD fragment ion spectrum of the identified peptide. $\mathbf{b}$ Fragment mass error distribution of the $\mathbf{b}$ - and $y$-ion series. 
bioRxiv preprint doi: https://doi.org/10.1101/2020.09.30.320721; this version posted October 1, 2020. The copyright holder for this preprint (which was not certified by peer review) is the author/funder, who has granted bioRxiv a license to display the preprint in perpetuity. It is made available under aCC-BY-NC-ND 4.0 International license.

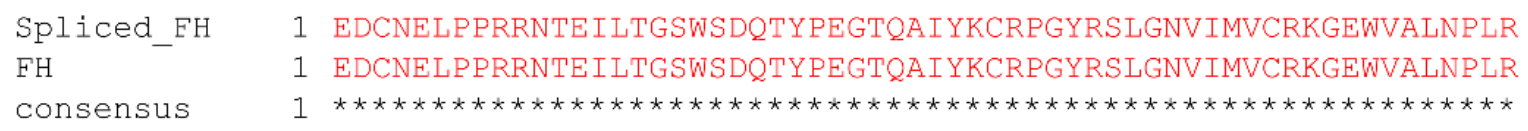

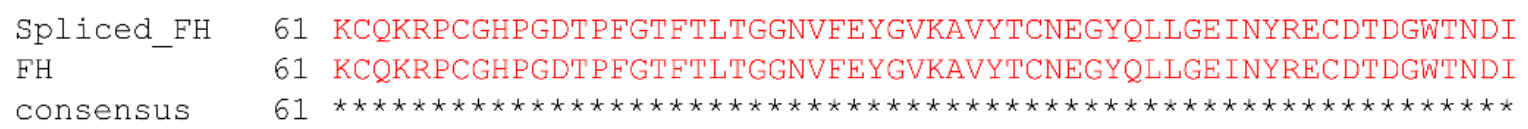

Spliced_FH 121 PICEVVKCLPVTAPENGKIVSSAMEPDREYHFGQAVRFVCNSGYKIEGDEEMHCSDDGFW FH - 121 PICEVVKCLPVTAPENGKIVSSAMEPDREYHFGQAVRFVCNSGYKIEGDEEMHCSDDGFW

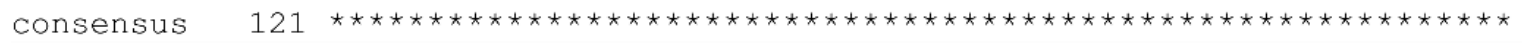

Spliced_FH 181 SKEKPKCVEISCKSPDVINGSPISQKIIYKENERFQYKCNMGYEYSERGDAVCTESGWRP FH 181 SKEKPKCVEISCKSPDVINGSPISQKIIYKENEREQYKCNMGYEYSERGDAVCTESGWRP

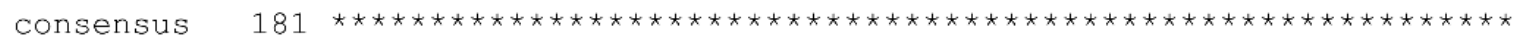

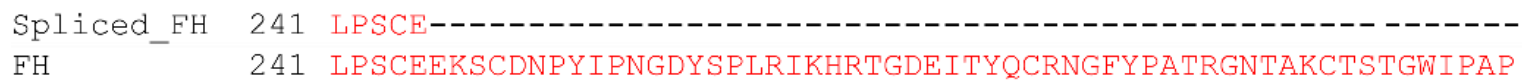

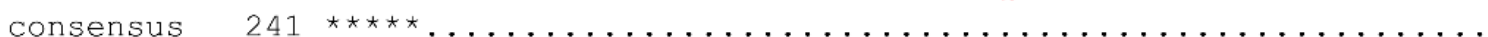

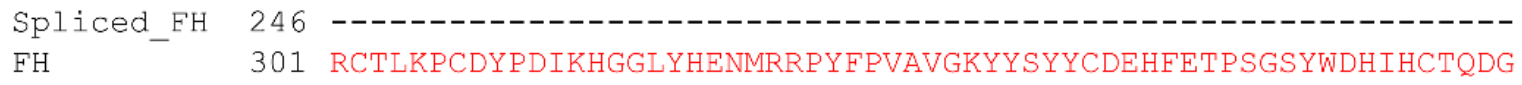

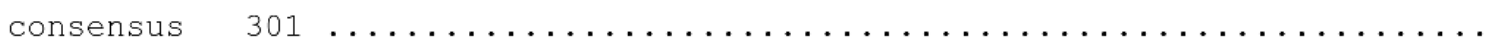

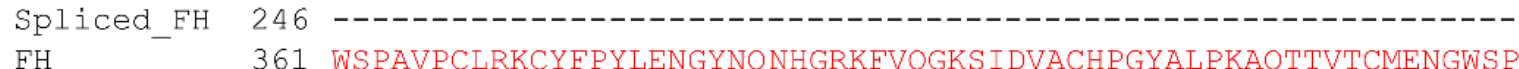

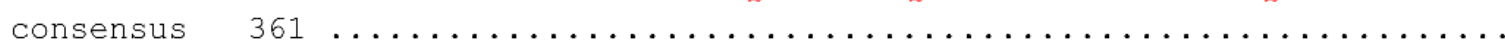

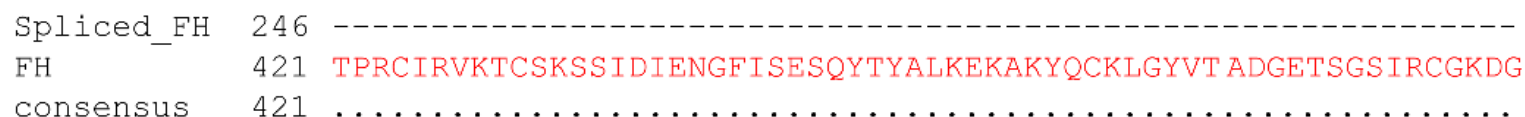

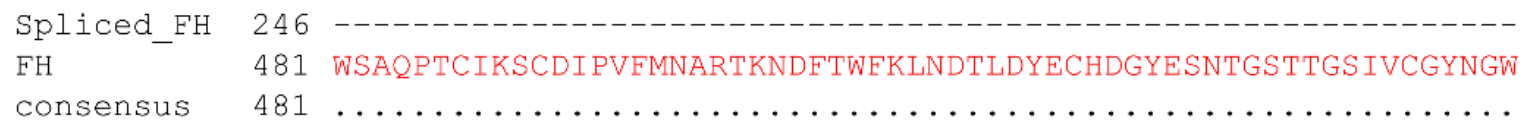

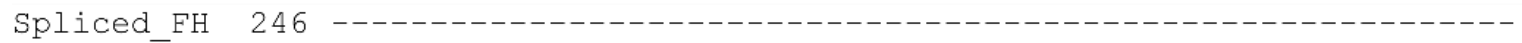

FH 541 SDLPICYERECELPKIDVHLVPDRKKDQYKVGEVLKESCKPGETIVGPNSVQCYHEGLSP

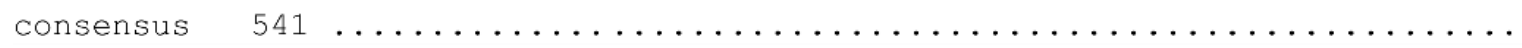

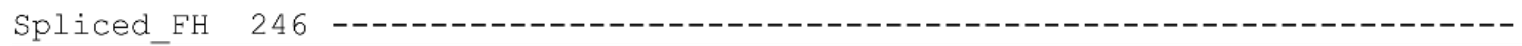

FH _ 601 DLPICKEQVQSCGPPPELINGNVKEKTKEEYGHSEVVEYYCNPRELMKGPNKIQCVDGEW

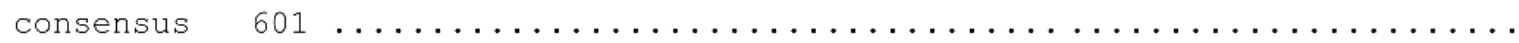

Spliced_FH 246 - 661 -

FH 661 TTLPVCIVEESTCGDIPELEHGWAQLSSPPYYYGDSVEFNCSESETMIGHRSITCIHGVW

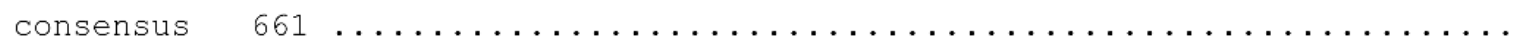


bioRxiv preprint doi: https://doi.org/10.1101/2020.09.30.320721; this version posted October 1,2020 . The copyright holder for this preprint (which was not certified by peer review) is the author/funder, who has granted bioRxiv a license to display the preprint in perpetuity. It is made available under aCC-BY-NC-ND 4.0 International license.

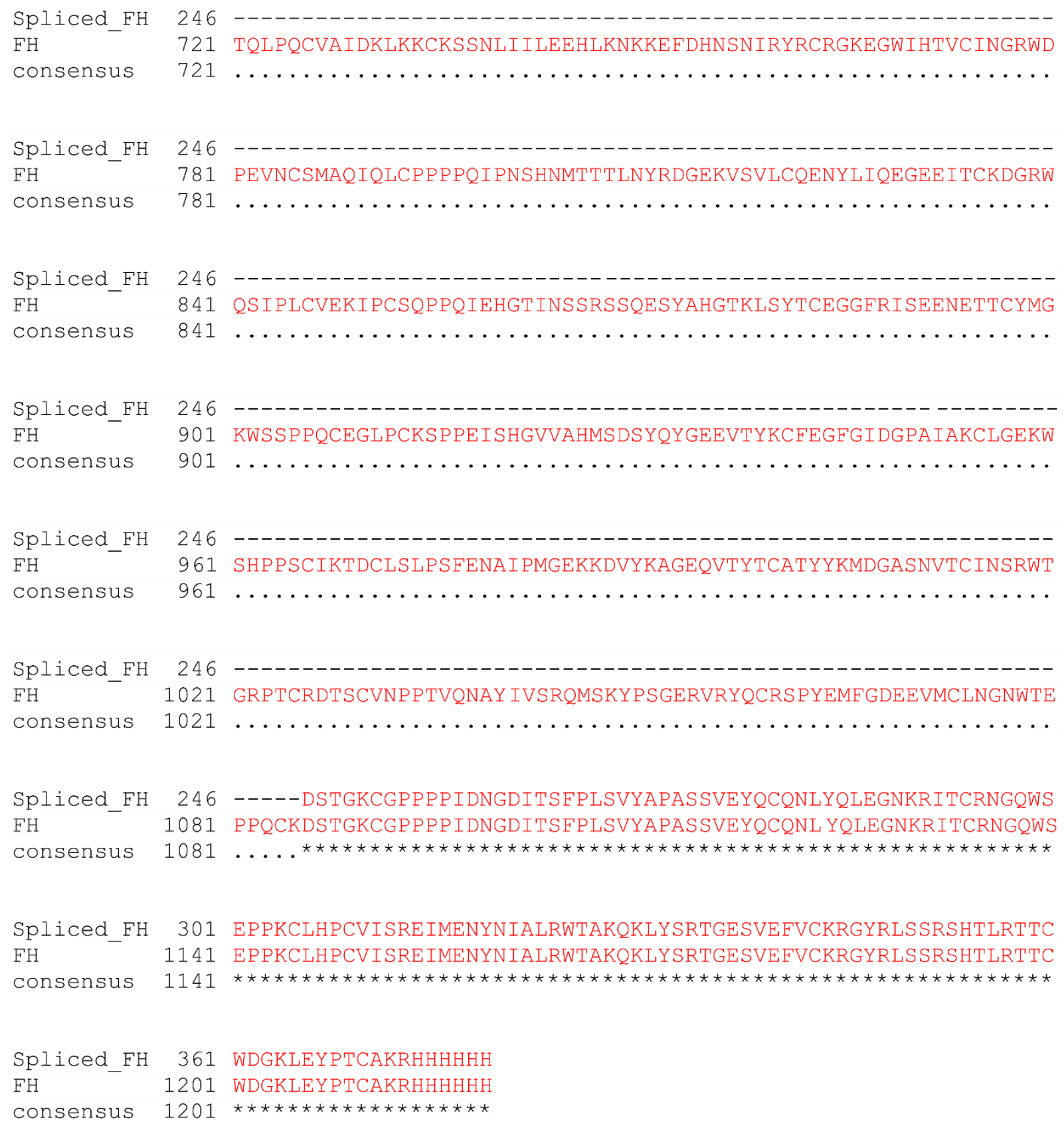
Supplementary Fig. 3: Pairwise sequence alignment of full-length and predicted FH isoform
based on experimentally verified transcript detected in RT-PCR. 
bioRxiv preprint doi: https://doi.org/10.1101/2020.09.30.320721; this version posted October 1, 2020. The copyright holder for this preprint (which was not certified by peer review) is the author/funder, who has granted bioRxiv a license to display the preprint in perpetuity. It is made available under aCC-BY-NC-ND 4.0 International license.

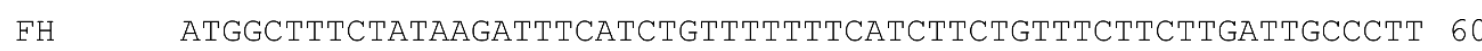

optifH ATGGCTTTCTACAAGATTCATCTGTTTTCTTCATCTTCTGCTTCTTCTTGATTGCCCTT 60

FH CCGTTCCACTCGTACGCCGAAGATTGCAATGAACTTCCTCCAAGAAGAAATACAGAAATT 120

optifH CCGTTCCACTCGTACGCCGAGGATTGCAACGAGCTTCCTCCAAGAAGAAACACAGAGATT 120

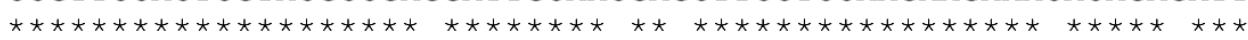

FH CTGACAgGTTCCTGgTCTGACCAAACATATCCAGAAGGCA CCCAGGCTATCTATAAATGC 180

optifH CTGACAGGTTCCTGGTCTGACCAGACATACCCAGAGGGCACCCAGGCTATCTACAAGTGC 180

$* * * * * * * * * * * * * * * * * * * * * * * * * * * * * * * * * * * * * * * * * * * * * * * * * * * * * * *$

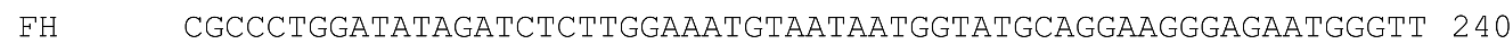

optifH CGCCCTGGATACAGATCTCTTGgAAACATCATCATGGTATGCAGGAAGGGAGAGTGGGTT 240

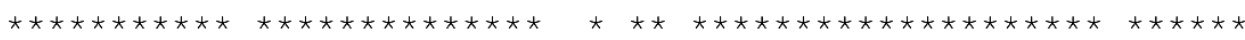

FH GCTCTTAATCCATTAAGgAAATtCAGAAAAGGCCCTGTGGACATCCTGGAGATACTCCT 300 optifH GCTCTTAACCCATTAAGGAAGTGCCAGAAGAGGCCCTGCGGACACCC TGGAGATACTCCT 300

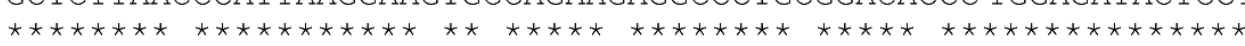

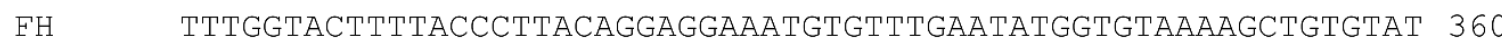

optifH TTCGGTACTTTCACCCTTACAGGAGGAAACGTGTTCGAGTACGGTGTAAAGGCTGTGTAC 360

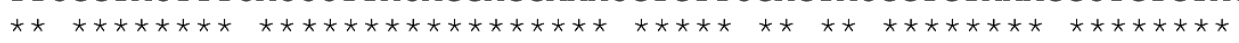

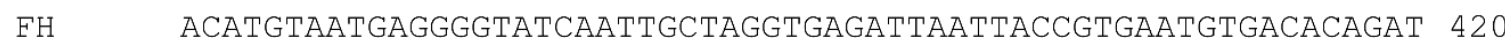

optifH ACATGCAACGAGGGGTACCAGTTGCTAGGTGAGATTAACTACCGTGAGTGCGACACAGAT 420

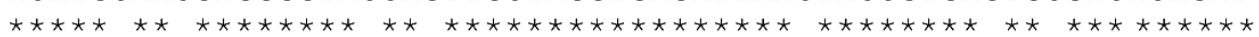

FH GgATGGACCAATGATATCCTATATGTGAagtTGTGAAGTGTTTACCAGTGACAGCACCA 480 optifH GGATGGACCAACGATATTCCTATCTGCGAGGTTGTGAAGTGCTTACCAGTGACAGCACCA 480

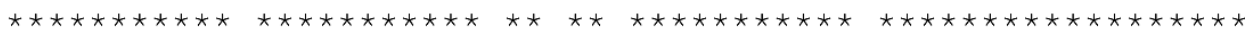

FH GAGAATGGAAAATTGTCAGTAGTGCAATGGAACCAGATCGGGAATACCATTTTGGACAA 540 optifH GAGAACGGAAAATTGTCAGTAGTGCAATGGAGCCAGATCGGGAGTACCACTTCGGACAG 540

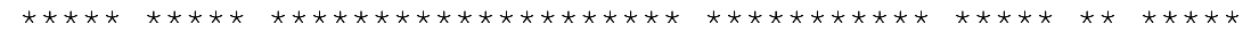

FH GCAGTACGGTTTGTATGTAACTCAGGCTACAAGATTGAAg GAGATGAAGAAATGCATTGT 600 optifH GCAGTACGGTTCGTATGCAACTCAGGCTACAAGATTGAGGGAGATGAGGAGATGCACTGC 600

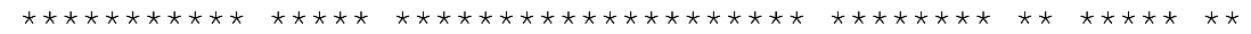

FH TCAGACGATGgTTTTTGGAgTAAAGAGAAACCAAAGTGTGTGGAAATTTCATGCAAATCC

optifH TCAGACGATGGTTTCTGGAGTAAGGAGAAGCCAAAGTGCGTGGAGATTTCATGCAAGTCC

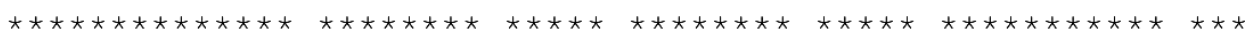

$\mathrm{FH}$

optiFH

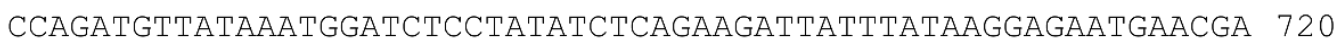
CCAGATGTTATCAACGGATCTCCTATCTCTCAGAAGATTATTTACAA GGAGAACGAGCGA 720

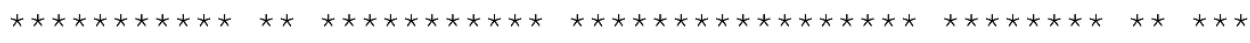

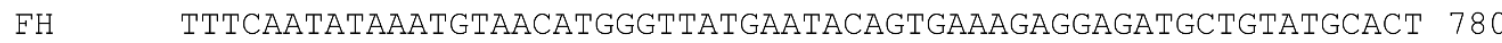
optifH TTCCAGTACAAGTGCAACATGGGTTACGAGTACAGTGAGAGAGGAGATGCTGTATGCACT 780

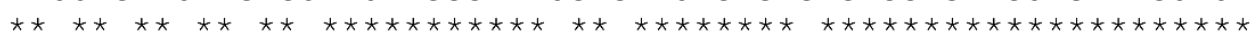

FH GAATCTGGATGGCGTCCGTTGCCTTCATGTGAAGAAAAATCATGTGATAATCCTTATATT 840 optifH GAGTCTGGATGGCGTCCGTTGCCTTCATGCGAGGAGAAGTCATGCGATAACCCTTACATT 840

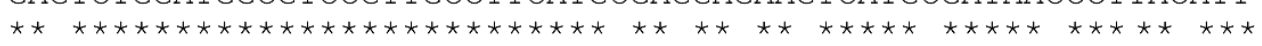

FH CCAAATGGGACTACTCACCTTTAAgGATTAAACACAGAACTGGAGATGAAATCACGTAC 900 optifH CCAAACGGTGACTACTCACCTTTAAGGATTAAGCACAGAACTGGAGATGAGATCACGTAC 900

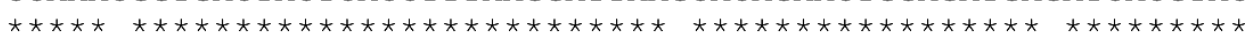


bioRxiv preprint doi: https://doi.org/10.1101/2020.09.30.320721; this version posted October 1, 2020. The copyright holder for this preprint (which was not certified by peer review) is the author/funder, who has granted bioRxiv a license to display the preprint in perpetuity. It is made available under aCC-BY-NC-ND 4.0 International license.

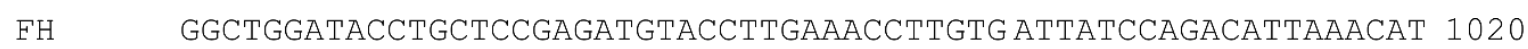
optifH GGCTGGATCCCTGCTCCGAGATGCACCTTGAAGCCTTGCGATTACCCAGACATTAAGCAC 1020

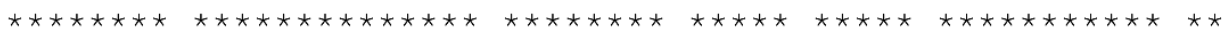

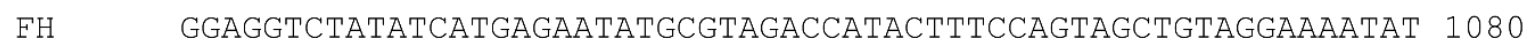
optifH GGAGGTCTATACCACGAGAATATGCGACGGCCTTATTTTCCGGTAGCTGTAGGAAAGTAC 1080

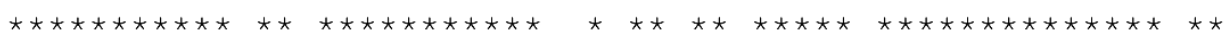

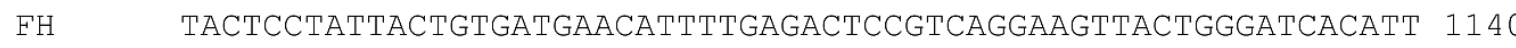
optifH TACTCCTACTACTGCGATGAGCACTTCGAGACTCCGTCAGGAAGTTACTGGGATCACATT 1140

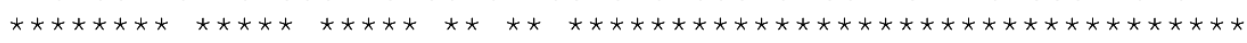

FH CATTGCACACAAGATGgATGgTCGCCAGCAGTACCATGCCTCAGAAAATGTTATTTTCCT 1200 optifH CACTGCACACAGGATGGATGGTCGCCAGCAGTACCATGCCTCAGAAAGTGCTACTTCCCT 1200

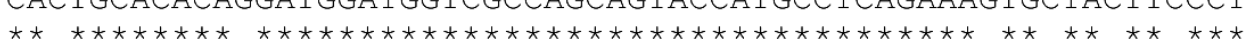

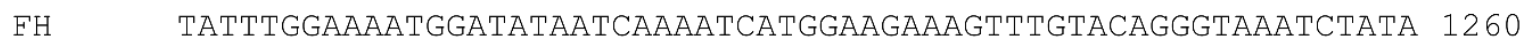
optifH TACTTGGAGAACGGATACAACCAGAACTACGGAAGAAAGTTCGTACAGGGTAAGTCTATC 1260

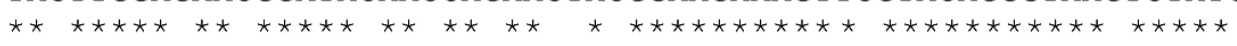

FH GACGTTGCCTGCCATCCTGGCTACGCTCTTCCAAAAGCGCAGACCACAGTTACATGTATG 1320 optifH GACGTTGCCTGCCACCCTGGCTACGCTCTTCCAAAGGCGCAGACCACAGTTACATGCATG 1320

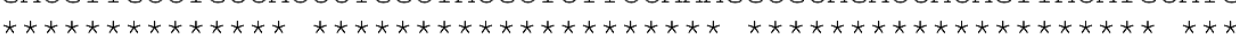

FH GAGAATGGCTGGTCTCCTACTCCCAGATGCATCCGTGTCAAAACATGTTCCAAATCAAGT 1380 optifH GAGAACGGCTGGTCTCCTACTCCCAGATGCATCCGTGTCAAGACATGCTCCAAGTCAAGT 1380

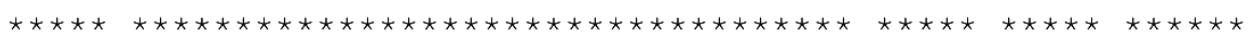

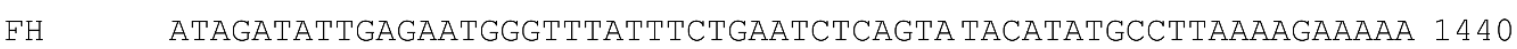
optifH ATCGATATTGAGAACGGTTCATTTCTGAGTCTCAGTACACATACGCCTTAAAGGAGAAG 1440

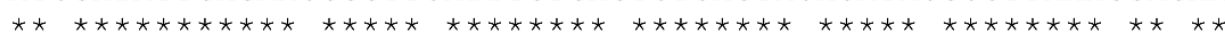

FH GCGAAATATCAATGCAAACTAGGATATGTAACAGCAGATGGTGAAACATCAGGATCAATT 1500 optifH GCGAAGTACCAGTGCAAGCTAGGATACGTAACAGCAGATGGTGAGACATCAGGATCAATT 1500

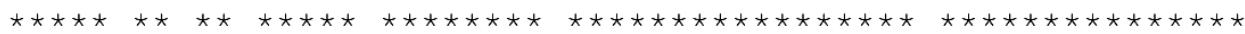

FH ACATGTGGGAAAGATGgATGgTCAgCTCAACCCACGTGCATTAAATCTTGTGATATCCCA 1560 optifH ACATGCGGGAAGGATGGATGGTCAGCTCAGCCCACGTGCA TTAAGTCTTGCGATATCCCA 1560

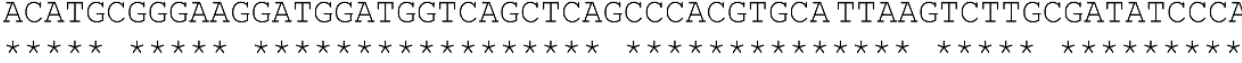

FH GTATTTATGAATGCCAGAACTAAAAATGACTTCACATGGTTTAAgCTGAATGACACATTG 1620 optifH GTATTCATGAACGCCAGAACTAAGAACGACTTCACATGGTTCAAGCTGAACGACACATTG 1620

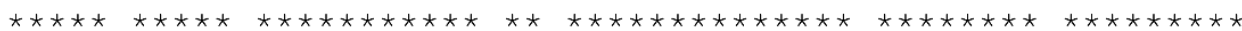

FH GACTATGAATGCCATGATGgtTATGAAAGCAATACTGGAAGCACCACTGGTTCCATAGTG 1680 optifH GACTACGAGTGCCACGATGGTTACGAGAGCAACACTGGAAGCACCACTGGTTCCATCGTG 1680

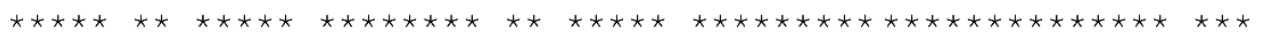

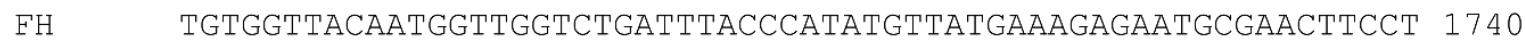

optifH TGCGGTTACAACGGTTGGTCTGATTTACCCATCTGCTACGAGAGAGAGTGCGAGCTTCCT 1740

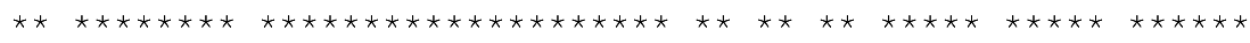

FH AAAATAGATGtACACTTAGTTCCTGATCGCAAGAAAGACCAGTATAAAGTTGGAGAGgTG 1800 optifH AAGATCGATGTACACTTAGTTCCTGATCGCAAGAAGGACCAGTACAAGGTTGGAGAGgTG 1800

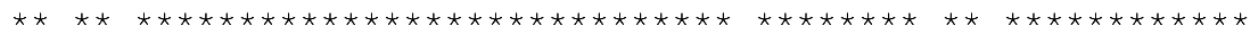

FH TTGAAATCTCCTGCAAACCAGGATTACAATAGTTGG ACCTAATTCCGTTCAGTGCTAC 1860 optifH TTGAAGTTCTCCTGCAAGCCAGGATTCACAATCGTTGGACCTAACTCCGTTCAGTGCTAC 1860

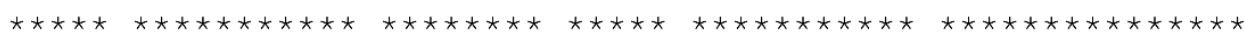


bioRxiv preprint doi: https://doi.org/10.1101/2020.09.30.320721; this version posted October 1, 2020. The copyright holder for this preprint (which was not certified by peer review) is the author/funder, who has granted bioRxiv a license to display the preprint in perpetuity. It is made available under aCC-BY-NC-ND 4.0 International license.

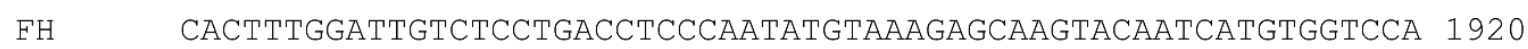
optifH CACTTCGgAtTGTCTCCTGACCtCCCAATCTGCAAGGAGCAGGTACAGTCATGTGGACCA 1920

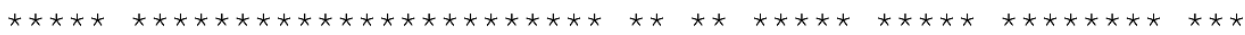

FH CCTCCTGAACTCCTCAATGgGAATGTAAGGAAAAAAGAAAgAagAATATGgACACAGT 1980 optifH CCACCAGAACTTCTCAACGGGAACGTTAAGGAGAAGACGAAGGAGGAGTACGGACACAGT 1980

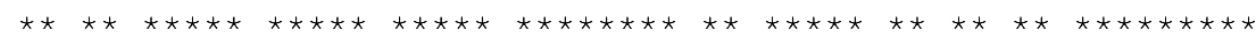

FH GAAgtgGtgaAtATtATtgCAATCCTAGATTTCTAATGAAgGGACCTAATAAAATTCAA 2040 optifH GAGGTGGTGGATACTACTGCAACCCTAGATTCCTAAT GAAGGGACCTAACAAGATTCAG 2040

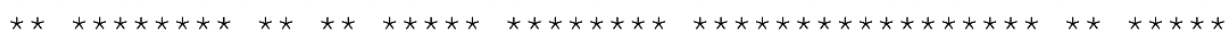

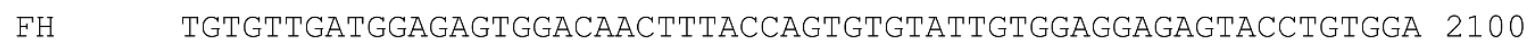
optifH TGCGTTGATGGAGAgTGGACAACTTTACCAGTGTGCATTGTGGAGGAGAGTACCTGCGGA 2100

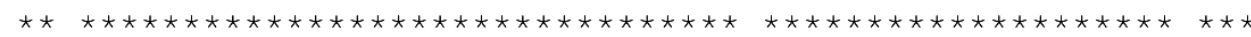

FH GAtATACCTGAACTTGAACATGGCTGGGCCCAGCTTTCTTCCCCTCCTTATtACTATGGA 2160 optifH GATATCCCTGAGCTTGAGCACGGCTGGGCCCAGCTTTCTTCCCCTCCTTACTACTACGGA 2160

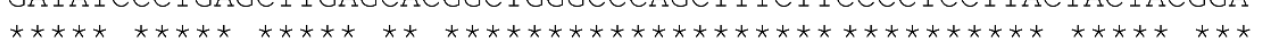

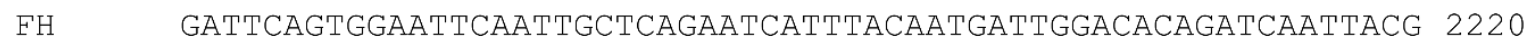
optifH GATTCAGTGGAGTTCAACTGCTCAGAGTCATTCACAATGATTGGACACAGATCAATTACG 2220

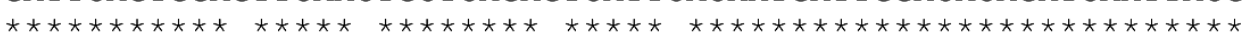

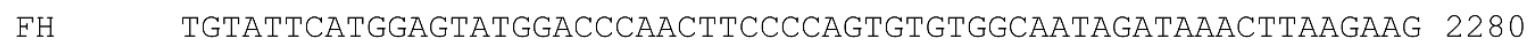
optifH TGCATTCACGGAGTATGGACCCAGCTTCCCCAGTGCGTGGCAATCGATAAGCTTAAGAAG 2280

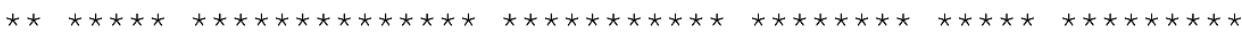

FH TGCAAATCATCAAATTAAATATACTTGAGGAACATTT AAAAAACAAGAAgGAATTCGAT 2340 optifH TGCAAGTCATCAAACTTAATTATCCTTGAGGAGCACTTAAAGAACAAGAAGGAGTTCGAT 2340

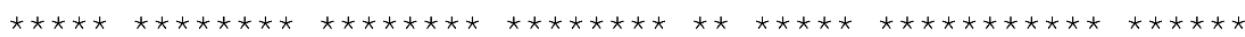

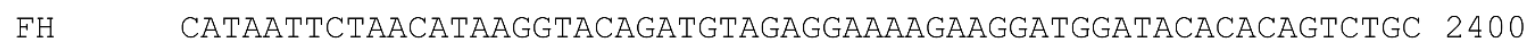

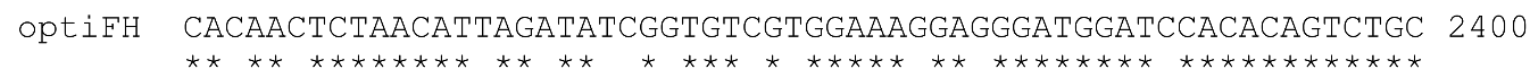

FH AtAAATGgAagAtgGgAtCCAGAAgtgAACTGCTCAATGGCACAAATACAATTATGCCCA 2460 optifH ATCAACGGAAGATGGGATCCAGAGGTGAACTGCTCAATGGCACAGATCCAGTTATGCCCA 2460

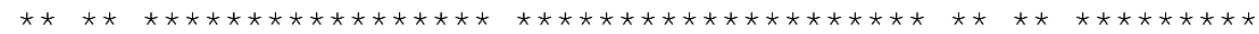

FH CCTCCACCTCAGATTCCCAATTCTCACAATATGACAACCACACTGAATTATCGgGATGgA 2520 optifH CCTCCACCTCAGATTCCCAACTCTCACAACATGACAACCACACTGAACTATCGAGACGGT 2520

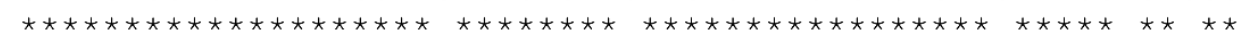

FH GAAAAAGTATCTGTTCTTTGCCAAGAAAATTATCTAATTCAGGAAGGAGAAGAAATTACA 2580 optifH GAAAAAGTTCAGTTCTTTGCCAGGAGAACTACCTAATTCAGGAGGGAGAGGAGATtACA 2580

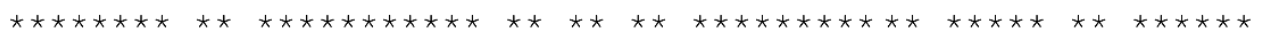

FH TGCAAAGATGGAagAtGgCAGTCAATACCACTCTGTGTTGAAAAAATTCCATGTTCACAA 2640 optifH TGCAAGGATGGAAGATGGCAGTCAATCCCACTCTGCGTTGAGAAGATTCCATGCTCACAG 2640

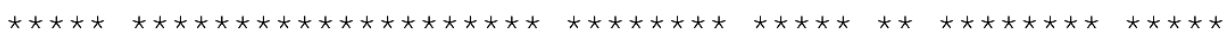

FH CCACCTCAgAtAgAaCACGgAaCCATtAATtCATCCAGGTCTTCACAAGAAAgtTAtgCA 2700 optifH CCACCTCAGATCGAGCACGGAACCATTAACTCATCCAGGTCTTCACAGGAGAGTTACGCA 2700

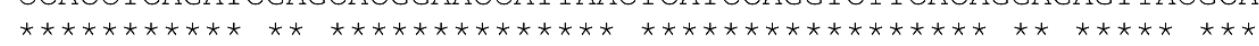

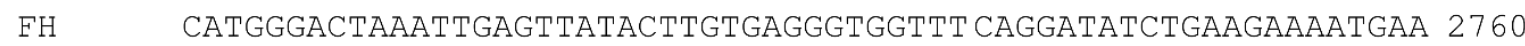
optifH CACGGGACTAAGTTGAGTACACTTGCGAGGGTGGTTTCAGGATCTCTGAGGAGAACGAG 2760

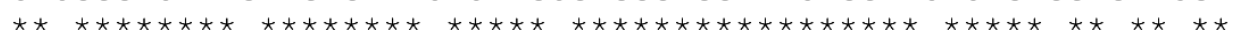


bioRxiv preprint doi: https://doi.org/10.1101/2020.09.30.320721; this version posted October 1, 2020. The copyright holder for this preprint (which was not certified by peer review) is the author/funder, who has granted bioRxiv a license to display the preprint in perpetuity. It is made available under aCC-BY-NC-ND 4.0 International license.

FH ACAACATGCTACATGgGAAAATGgAgTtCTCCACCTCAgTGTGAAGGCCTTCCTTGTAAA 2820

optifH ACAACATGCTACATGGGAAGTGGAGTTCTCCACCTCAGTGCGAGGGCCTTCCTTGCAAG 2820

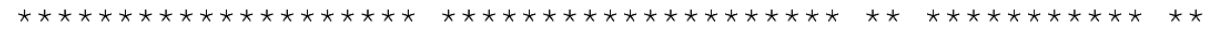

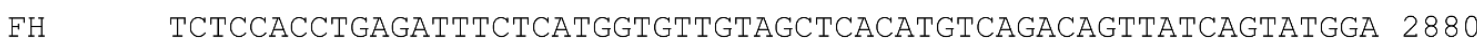

optifH TCTCCACCTGAGATTCTCACGGTGTTGAGCTCACA TGTCAGACAGTTACCAGTACGGA 2880

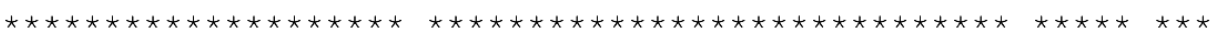

FH GAAGAAGTTACGTACAAATGTTTTGAAGGTTTTGGAATTGATGGGCCTGCAATTGCAAAA 2940

optifH GAGGAGGTTACGTACAAGTGCTTCGAGGGTTTCGGAATTGATGGGCCTGCAATTGCAAAG 2940

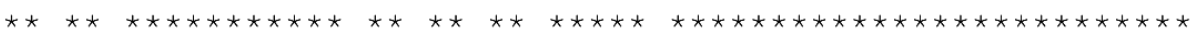

FH TGCTTAGGAGAAAAATGTCTCACCCTCCATCATGCATAAAAACAGATTGTCTCAGTTTA 3000

optifH TGCTTAGGAGAGAAGTGGTCTCACCCTCCATCATGCATCAAGACAGATTGCCTCAGTTTA 3000

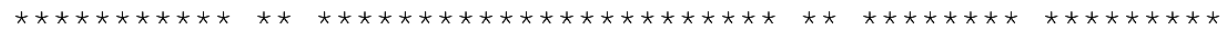

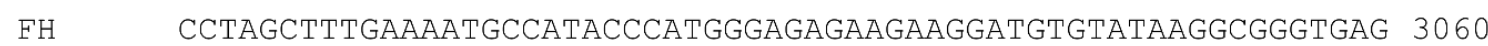

optifH CCTAGCTTCGAGAACGCCATCCCCATGGGAGAGAAGAAGGATGTGTACAAGGCGGGTGAG 3060

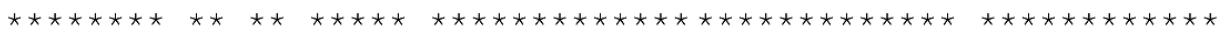

FH CAAGTGACTTACACTTGTGCAACATATTACAAAATGGATGGAGCCAGTAATGTAACATGC 3120

optifH CAgGTGACTTACACTTGCGCAACATACTACAAGATGGATGGAGCCAGTAACGTAACATGC 3120

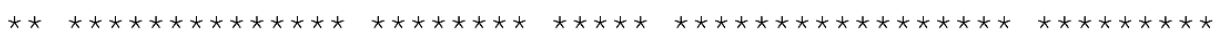

FH ATtAATAGCAGATGGACAGGAAgGCCAACATGCAGAGACACCTCCTGTGTGAATCCGCCC 3180

optifH ATTAACAGCCGATGGACTGGTCGTCCTACGTGCAGAGACACCTCCTGCGTGAACCCGCCC 3180

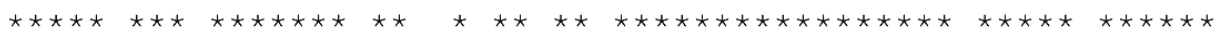

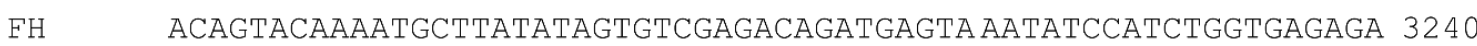

optifH ACAgtACAGAACGCTtACATCGTGTCGAGACAGATGAGTAAGTACCCATCTGGTGAGAGA 3240

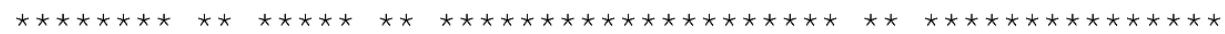

FH GTACGTTATCAATGTAGGAGCCCTTATGAAATGTTTGGGGATGAAGAAGTGATGTGTTTA 3300

optifH GTACGTTACCAGTGCAGGAGCCCTTACGAGATGTTCGGGGATGAGGAGGTGATGTGCTTA 3300

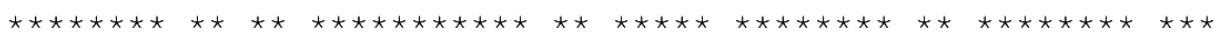

FH AATGGAAACTGGACGGAACCACCTCAATGCAAAGATTCTACAGGAAAATGTGGGCCCCCT 3360

optifH AACGGAAACTGGACGGAGCCACCTCAGTGCAAGGACTCGACA GGAAAGTGCGGGCCCCCT 3360

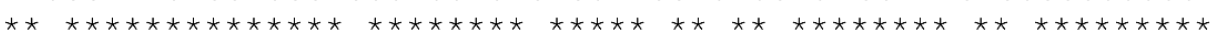

FH CCACCTATtGACAATGgGaCATtACTTCATTCCCGTTGTCAGTATATGCTCCAGCTTCA 3420

optifH CCACCTATTGACAACGGGGACATTACTTCATTCCCGTTGTCAGTATACGCTCCAGCTTCA 3420

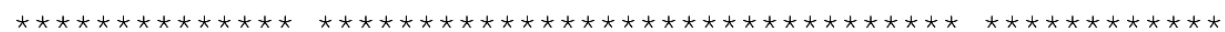

FH TCAGTTGAgtACCAATGCCAGAACTTGTATCAACTTGAGGGTAACAAGCGAATAACATGT 3480

optifH TCAGTTGAGTACAGTGCCAGAACTTGTACCAGCTTGAGGGTAACAAGCGAATCACATGC 3480

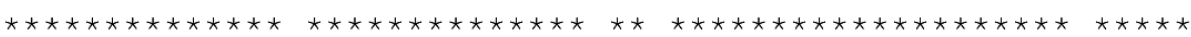

FH AGAAATGGACAATGGTCAGAACCACCAAAATGCTTACATCCGTGTGTAATATCCCGAGAA 3540

optifH AGAAACGGACAGTGGTCAGAGCCACCAAAGTGCTTACACCCGTGCGTAATCTCCCGAGAG 3540

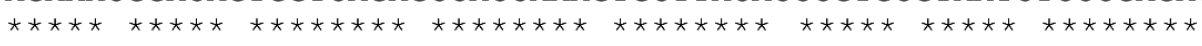

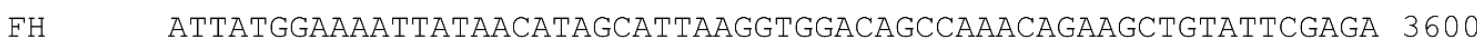

optifH ATTATGGAGAACTACAACATCGCATTAAGGTGGACAGCCAAGCAGAAGCTGTACTCGAGA 3600

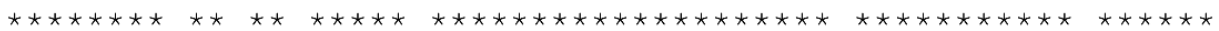

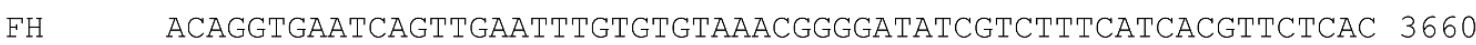

optifH ACAGGTGAGTCAGTTGAGTTCGTGTGCAAGCGGGGATACCGTCTTTCATCACGTTCTCAC 3660

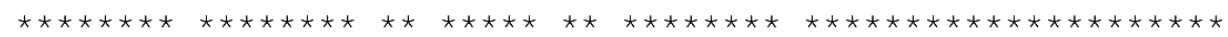

FH ACATTGCGAACAACATGTTGgGATGgGAACTGGAGTATCC AACTTGTGCAAAAAgATAA 3720

optifH ACATTGCGAACAACATGCTGGGATGGGAAGCTGGAGTACCCAACTTGCGCAAAGAGATAA 3720

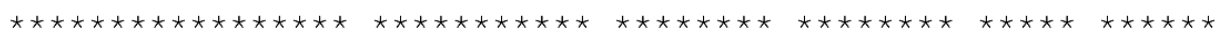


bioRxiv preprint doi: https://doi.org/10.1101/2020.09.30.320721; this version posted October 1, 2020. The copyright holder for this preprint (which was not certified by peer review) is the author/funder, who has granted bioRxiv a license to display the preprint in perpetuity. It is made available under aCC-BY-NC-ND 4.0 International license.

Supplementary Fig. 4: Pairwise sequence alignment of FH and optiFH 

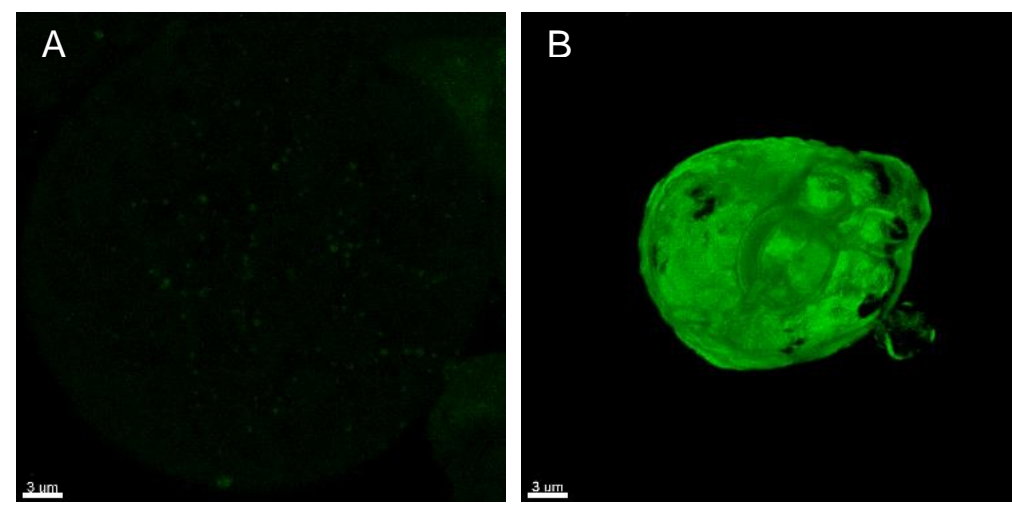

Supplementary Fig. 5: 3D rendered confocal Z-stacks of moss protoplasts transfected with FHCitrine (A) and optiFH-Citrine (B). Scale bar is $3 \mu \mathrm{m}$. 


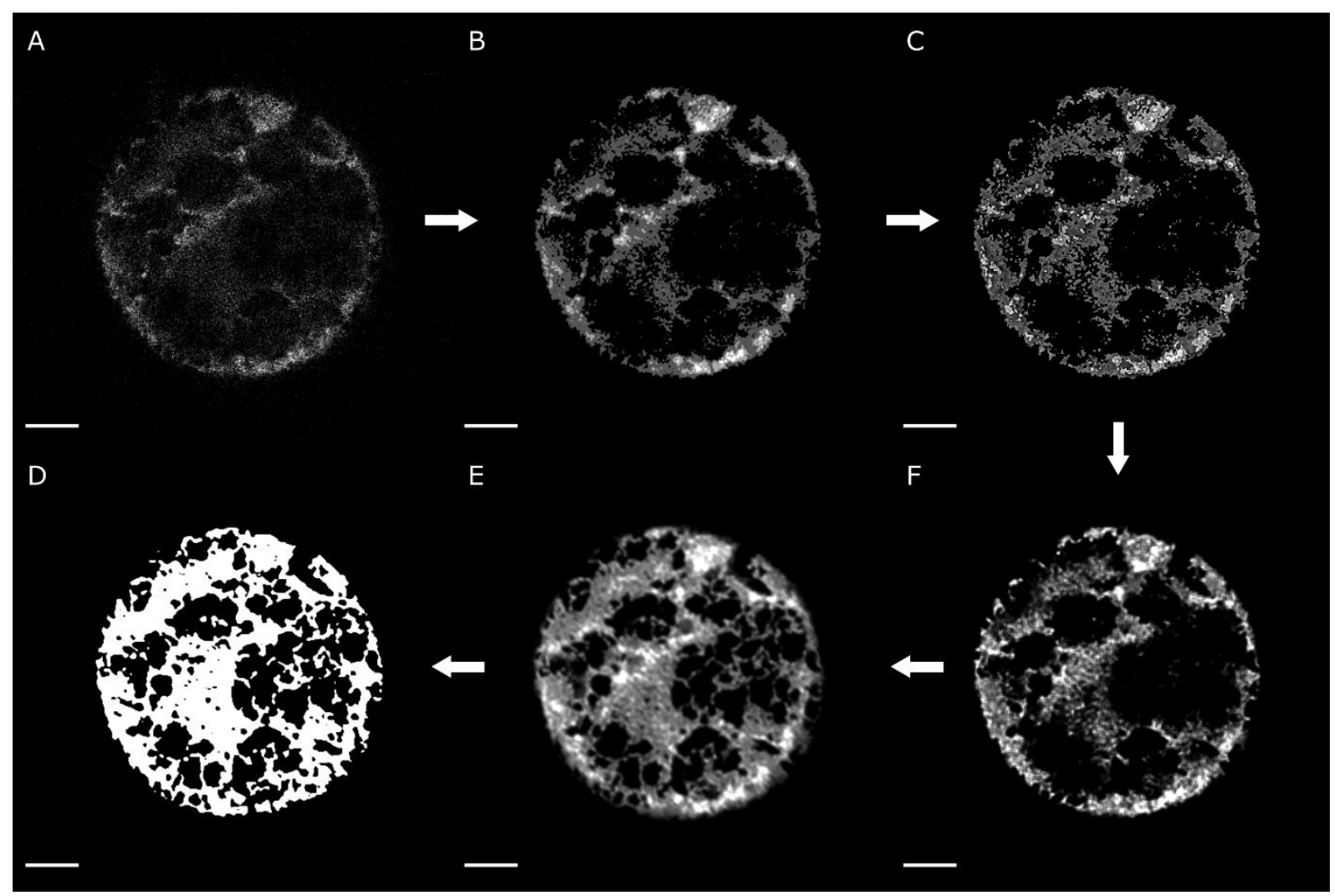

Supplementary Fig. 6: The workflow of the image processing steps demonstrated with an exemplary single slice from a FIX-Citrine cell. The original, raw image from the microscope (A) was first processed with a median filter (B). The resulting image was subjected to an unsharp-mask operation (C). Afterwards, a Richardson-Lucy restoration algorithm was implemented (F). The preprocessing was completed with a local intensity equalization operation $(\mathrm{E})$. The final version of the image was then thresholded using a local adaptive Otsu thresholding method, leading to the binary masks (D) that were subsequently used for selection of the voxels for quantification. Scale bar is $5 \mu \mathrm{m}$. 
bioRxiv preprint doi: https://doi.org/10.1101/2020.09.30.320721: this version posted October 1, 2020. The copyright holder for this preprint (which was not certified by peer review) is the author/funder, who has granted bioRxiv a license to display the preprint in perpetuity. It is made available under aCC-BY-NC-ND 4.0 International license.

Supplementary Table 1: Moss microRNAs targeting human FIX CDS. Analysis was performed using psRNAtarget (http://plantgrn.noble.org/v1_psRNATarget/). The miRNAs as well as their binding sites, expectation score, maximum energy to unpair the target site (UPE) and mode of action of miRNAs are shown.

\begin{tabular}{|c|c|c|c|c|c|c|}
\hline MicroRNA & & Alignment & & Expectation & UPE & Mode of action \\
\hline miR1044-3P & $\begin{array}{l}\text { miRNA } 20 \\
\text { Target } 1304\end{array}$ & $\begin{array}{l}\text { UUUUGUUUAUACGUGAUGUU } \\
:: \text { : : : : : : : : : : : : : } \\
\text { AAGGCAAAUAUGGAAUAUAU }\end{array}$ & 1 & 5 & 13.996 & Cleavage \\
\hline $\operatorname{miR} 1028 c-3 p$ & $\begin{array}{l}\text { miRNA } 21 \\
\text { Target } 495\end{array}$ & $\begin{array}{l}\text { CGAGA-AUUUGGAUGUUACGGU } \\
: \quad: \quad: \quad:-:::: \quad .:: \quad::::: \\
\text { GUCCUGUGAACCAGCAGUGCCA }\end{array}$ & $\begin{array}{l}1 \\
516\end{array}$ & 5 & 21.847 & Translational inhibition \\
\hline
\end{tabular}


Supplementary Table 2: The donor splice sites for all 87,533 annotated transcripts corresponding to the 32,926 protein-encoding genes of the current $\boldsymbol{P}$. patens genome release v3.3.

\begin{tabular}{|c|c|c|c|c|c|c|c|c|}
\hline Motif & Count & Percentage (\%) & Motif & Count & Percentage (\%) & Motif & Count & Percentage (\%) \\
\hline CAGGT & 113,285 & 22.5460 & TAAGT & 1,610 & 0.3204 & $A G A G C$ & 44 & 0.0088 \\
\hline$A A G G T$ & 84,769 & 16.8708 & AGTGT & 1,530 & 0.3045 & GCTGC & 44 & 0.0088 \\
\hline GAGGT & 57,630 & 11.4695 & $T G A G T$ & 1,492 & 0.2969 & ATCAT & 41 & 0.0082 \\
\hline CTGGT & 20,698 & 4.1193 & $A A G G C$ & 1,487 & 0.2959 & CGGGC & 41 & 0.0082 \\
\hline ATGGT & 18,574 & 3.6966 & CTCGT & 1,385 & 0.2756 & GATGC & 41 & 0.0082 \\
\hline TTGGT & 15,064 & 2.9980 & GGAGT & 1,330 & 0.2647 & TTTGC & 40 & 0.0080 \\
\hline TAGGT & 12,835 & 2.5544 & ATCGT & 1,273 & 0.2534 & TCGGC & 39 & 0.0078 \\
\hline CAAGT & 12,206 & 2.4292 & GACGT & 1,273 & 0.2534 & GCGGC & 36 & 0.0072 \\
\hline GTGGT & 9,443 & 1.8793 & GTTGT & 1,259 & 0.2506 & GGGGC & 36 & 0.0072 \\
\hline ACGGT & 9,246 & 1.8401 & TTCGT & 985 & 0.1960 & GGAGC & 35 & 0.0070 \\
\hline TGGGT & 9,034 & 1.7980 & GAGGC & 981 & 0.1952 & CATGC & 34 & 0.0068 \\
\hline$A G G G T$ & 8,314 & 1.6547 & ACCGT & 914 & 0.1819 & TCAGC & 33 & 0.0066 \\
\hline TCGGT & 7,588 & 1.5102 & TACGT & 908 & 0.1807 & CCGGC & 32 & 0.0064 \\
\hline CGGGT & 6,757 & 1.3448 & CTAGT & 879 & 0.1749 & TTCGC & 32 & 0.0064 \\
\hline$A A A G T$ & 6,677 & 1.3289 & CGTGT & 870 & 0.1731 & ATTGC & 31 & 0.0062 \\
\hline CCGGT & 6,223 & 1.2385 & ATAGT & 856 & 0.1704 & CTTGC & 31 & 0.0062 \\
\hline GCGGT & 6,059 & 1.2059 & CCCGT & 804 & 0.1600 & GGTGC & 30 & 0.0060 \\
\hline AATGT & 5,632 & 1.1209 & TCCGT & 742 & 0.1477 & TCTGC & 30 & 0.0060 \\
\hline CATGT & 5,495 & 1.0936 & TGCGT & 673 & 0.1339 & AGTGC & 28 & 0.0056 \\
\hline GGGGT & 5,371 & 1.0689 & $A G C G T$ & 665 & 0.1323 & TGTGC & 26 & 0.0052 \\
\hline GAAGT & 4,718 & 0.9390 & GCCGT & 516 & 0.1027 & CTCGC & 23 & 0.0046 \\
\hline GATGT & 4,086 & 0.8132 & TTAGT & 506 & 0.1007 & TGCGC & 23 & 0.0046 \\
\hline CTTGT & 3,916 & 0.7794 & GTCGT & 406 & 0.0808 & ACTGC & 22 & 0.0044 \\
\hline ATTGT & 3,638 & 0.7240 & CGCGT & 396 & 0.0788 & GAAAT & 22 & 0.0044 \\
\hline$A G A G T$ & 2,987 & 0.5945 & GGTGT & 336 & 0.0669 & CCTGC & 21 & 0.0042 \\
\hline CCTGT & 2,979 & 0.5929 & GTAGT & 300 & 0.0597 & GGCGC & 19 & 0.0038 \\
\hline ACTGT & 2,904 & 0.5780 & GGCGT & 244 & 0.0486 & TACGC & 19 & 0.0038 \\
\hline CAGGC & 2,860 & 0.5692 & CTGGC & 221 & 0.0440 & ACAGC & 18 & 0.0036 \\
\hline GCTGT & 2,830 & 0.5632 & ATGGC & 199 & 0.0396 & GTTGC & 18 & 0.0036 \\
\hline TCTGT & 2,772 & 0.5517 & TAGGC & 181 & 0.0360 & ATCGC & 17 & 0.0034 \\
\hline TTTGT & 2,553 & 0.5081 & TTGGC & 89 & 0.0177 & TTAGC & 17 & 0.0034 \\
\hline ACAGT & 2,426 & 0.4828 & CAAGC & 65 & 0.0129 & TGAGC & 16 & 0.0032 \\
\hline$C C A G T$ & 2,286 & 0.4550 & $A A A G C$ & 55 & 0.0109 & AACGC & 15 & 0.0030 \\
\hline CACGT & 2,273 & 0.4524 & GAAGC & 55 & 0.0109 & CCAGC & 15 & 0.0030 \\
\hline AACGT & 1,965 & 0.3911 & TGGGC & 54 & 0.0107 & GACGC & 15 & 0.0030 \\
\hline GCAGT & 1,948 & 0.3877 & AATGC & 52 & 0.0103 & GTCGC & 15 & 0.0030 \\
\hline TATGT & 1,894 & 0.3769 & GTGGC & 52 & 0.0103 & GTCAT & 14 & 0.0028 \\
\hline$T C A G T$ & 1,882 & 0.3746 & ACGGC & 47 & 0.0094 & TATGC & 14 & 0.0028 \\
\hline CGAGT & 1,876 & 0.3734 & $A G G G C$ & 46 & 0.0092 & GTAGC & 13 & 0.0026 \\
\hline TGTGT & 1,656 & 0.3296 & GCAGC & 46 & 0.0092 & TCCGC & 13 & 0.0026 \\
\hline
\end{tabular}



made available under aCC-BY-NC-ND 4.0 International license.

\begin{tabular}{|c|c|c|c|c|c|}
\hline Motif & Count & Percentage (\%) & Motif & Count & Percentage (\%) \\
\hline$A A G A T$ & 12 & 0.0024 & TGCAT & 4 & 0.0008 \\
\hline AGCGC & 12 & 0.0024 & $A G A A T$ & 3 & 0.0006 \\
\hline ATAGC & 12 & 0.0024 & ATGAT & 3 & 0.0006 \\
\hline CGTGC & 12 & 0.0024 & GCTAT & 3 & 0.0006 \\
\hline CTAGC & 12 & 0.0024 & TAATG & 3 & 0.0006 \\
\hline CGAGC & 11 & 0.0022 & TTGAT & 3 & 0.0006 \\
\hline$A A A A T$ & 10 & 0.0020 & ATAAT & 2 & 0.0004 \\
\hline CAAAT & 10 & 0.0020 & CAACT & 2 & 0.0004 \\
\hline CACGC & 10 & 0.0020 & CCAAT & 2 & 0.0004 \\
\hline CCCGC & 10 & 0.0020 & GACTA & 2 & 0.0004 \\
\hline GCCGC & 10 & 0.0020 & GATAT & 2 & 0.0004 \\
\hline ACCAT & 9 & 0.0018 & TAATA & 2 & 0.0004 \\
\hline TAAGC & 9 & 0.0018 & TGAAA & 2 & 0.0004 \\
\hline TCAAT & 9 & 0.0018 & TGGAT & 2 & 0.0004 \\
\hline ATTAT & 8 & 0.0016 & CTGAT & 1 & 0.0002 \\
\hline GCAAT & 8 & 0.0016 & CTGTG & 1 & 0.0002 \\
\hline TCTAT & 8 & 0.0016 & CTTAT & 1 & 0.0002 \\
\hline CATAT & 6 & 0.0012 & GGTAA & 1 & 0.0002 \\
\hline TAGAT & 6 & 0.0012 & TAAAT & 1 & 0.0002 \\
\hline TATAT & 6 & 0.0012 & TAACA & 1 & 0.0002 \\
\hline$A C C G C$ & 5 & 0.0010 & TAAGA & 1 & 0.0002 \\
\hline CAGAT & 5 & 0.0010 & TAGAG & 1 & 0.0002 \\
\hline CGCGC & 5 & 0.0010 & TGATG & 1 & 0.0002 \\
\hline TCGAT & 5 & 0.0010 & TGCTT & 1 & 0.0002 \\
\hline TTCAT & 5 & 0.0010 & TTGTC & 1 & 0.0002 \\
\hline TTTAT & 5 & 0.0010 & TTTCG & 1 & 0.0002 \\
\hline TAAGG & 4 & 0.0008 & TTTTA & 1 & 0.0002 \\
\hline TGAGG & 4 & 0.0008 & TTTTT & 1 & 0.0002 \\
\hline
\end{tabular}


Supplementary Table 3: The acceptor splice sites for all 87,533 annotated transcripts corresponding to the 32,926 protein-encoding genes of the current $\boldsymbol{P}$. patens genome release v3.3.

\begin{tabular}{|c|c|c|c|c|c|}
\hline Motif & Count & Percentage (\%) & Motif & Count & Percentage (\%) \\
\hline CAGGT & 90,834 & 18.0778 & AAGTG & 669 & 0.1331 \\
\hline CAGGA & 54,132 & 10.7734 & TAGCG & 609 & 0.1212 \\
\hline CAGAT & 45,474 & 9.0503 & $A A G A G$ & 591 & 0.1176 \\
\hline CAGGG & 36,713 & 7.3066 & $A A G A C$ & 547 & 0.1089 \\
\hline CAGGC & 36,350 & 7.2344 & $A A G C A$ & 440 & 0.0876 \\
\hline CAGAA & 22,672 & 4.5122 & GAGGT & 365 & 0.0726 \\
\hline CAGAG & 21,613 & 4.3014 & $A A G C C$ & 315 & 0.0627 \\
\hline TAGGT & 19,555 & 3.8918 & AAGTA & 285 & 0.0567 \\
\hline CAGTT & 19,239 & 3.8290 & AAGTC & 273 & 0.0543 \\
\hline CAGCT & 18,854 & 3.7523 & $A A G C G$ & 238 & 0.0474 \\
\hline CAGTG & 15,897 & 3.1638 & GAGGA & 185 & 0.0368 \\
\hline CAGAC & 14,770 & 2.9395 & GAGAT & 182 & 0.0362 \\
\hline CAGCA & 11,526 & 2.2939 & GAGGG & 168 & 0.0334 \\
\hline TAGGA & 9,029 & 1.7970 & GAGGC & 160 & 0.0318 \\
\hline CAGCC & 8,266 & 1.6451 & GAGAA & 126 & 0.0251 \\
\hline CAGTC & 7,702 & 1.5329 & GAGTG & 108 & 0.0215 \\
\hline TAGGG & 7,378 & 1.4684 & GAGAG & 100 & 0.0199 \\
\hline TAGAT & 7,164 & 1.4258 & GAGCT & 80 & 0.0159 \\
\hline CAGTA & 6,745 & 1.3424 & GAGTT & 77 & 0.0153 \\
\hline TAGGC & 6,040 & 1.2021 & GAGAC & 69 & 0.0137 \\
\hline CAGCG & 6,004 & 1.1949 & GAGCA & 67 & 0.0133 \\
\hline AAGGT & 4,063 & 0.8086 & CACAT & 51 & 0.0102 \\
\hline TAGAG & 2,667 & 0.5308 & GAGTC & 48 & 0.0096 \\
\hline TAGAA & 2,624 & 0.5222 & GAGTA & 46 & 0.0092 \\
\hline TAGTT & 2,554 & 0.5083 & GAGCG & 39 & 0.0078 \\
\hline TAGTG & 2,225 & 0.4428 & GAGCC & 37 & 0.0074 \\
\hline TAGCT & 2,183 & 0.4345 & CACGC & 26 & 0.0052 \\
\hline TAGAC & 2,119 & 0.4217 & CACAA & 16 & 0.0032 \\
\hline AAGGA & 1,792 & 0.3566 & TACCT & 14 & 0.0028 \\
\hline$A A G G C$ & 1,483 & 0.2951 & CACAC & 11 & 0.0022 \\
\hline TAGCA & 1,480 & 0.2946 & CACGG & 10 & 0.0020 \\
\hline AAGAT & 1,342 & 0.2671 & TACAC & 10 & 0.0020 \\
\hline AAGGG & 1,107 & 0.2203 & CACGT & 8 & 0.0016 \\
\hline TAGTC & 967 & 0.1925 & TACAT & 8 & 0.0016 \\
\hline TAGCC & 916 & 0.1823 & CACAG & 6 & 0.0012 \\
\hline$A A G A A$ & 784 & 0.1560 & TACAA & 6 & 0.0012 \\
\hline TAGTA & 757 & 0.1507 & TACGA & 6 & 0.0012 \\
\hline AAGTT & 685 & 0.1363 & TACGC & 6 & 0.0012 \\
\hline$A A G C T$ & 671 & 0.1335 & AACGT & 5 & 0.0010 \\
\hline
\end{tabular}


bioRxiv preprint doi: https://doi.org/10.1101/2020.09.30.320721; this version posted October 1, 2020. The copyright holder for this preprint (which was not certified by peer review) is the author/funder, who has granted bioRxiv a license to display the preprint in perpetuity. It is made available under aCC-BY-NC-ND 4.0 International license.

\begin{tabular}{l|ccc|cc} 
Motif & Count & Percentage (\%) & Motif & Count & Percentage (\%) \\
\hline AGAAT & 5 & 0.0010 & ACGAT & 1 & 0.0002 \\
CACCT & 4 & 0.0008 & AGCAT & 1 & 0.0002 \\
AACAA & 3 & 0.0006 & ATAAT & 1 & 0.0002 \\
AGGAT & 3 & 0.0006 & CATCT & 1 & 0.0002 \\
CACCA & 3 & 0.0006 & CTAAT & 1 & 0.0002 \\
CACTA & 3 & 0.0006 & CTGGC & 1 & 0.0002 \\
TACGT & 3 & 0.0006 & GATAT & 1 & 0.0002 \\
TACTC & 3 & 0.0006 & GCTAT & 1 & 0.0002 \\
AACAG & 2 & 0.0004 & GCTTC & 1 & 0.0002 \\
AACTT & 2 & 0.0004 & GGAAG & 1 & 0.0002 \\
ACTAA & 2 & 0.0004 & GGTAT & 1 & 0.0002 \\
CACTG & 2 & 0.0004 & GTGAT & 1 & 0.0002 \\
CACTT & 2 & 0.0004 & GTTAT & 1 & 0.0002 \\
GAAAT & 2 & 0.0004 & NAGGA & 1 & 0.0002 \\
GAACT & 2 & 0.0004 & NAGGG & 1 & 0.0002 \\
GACAA & 2 & 0.0004 & NAGTG & 1 & 0.0002 \\
GACAT & 2 & 0.0004 & TACCG & 1 & 0.0002 \\
GCAAT & 2 & 0.0004 & TACTA & 1 & 0.0002 \\
GCCAT & 2 & 0.0004 & TACTG & 1 & 0.0002 \\
GGCAT & 2 & 0.0004 & TGCGT & 1 & 0.0002 \\
GGGAT & 2 & 0.0004 & TGTGA & 1 & 0.0002 \\
AACAT & 1 & 0.0002 & TTATT & 1 & 0.0002 \\
ACCAT & 1 & 0.0002 & TTTAC & 1 & 0.0002 \\
& & & & & \\
& 2 & & & 1 & 1 \\
\end{tabular}

